\title{
Probabilistic Seismic Demand Modeling of Local Level Response Parameters of an RC Frame
}

\author{
Fabio Freddi ${ }^{\mathrm{a}}$, Jamie Ellen Padgett ${ }^{\mathrm{b}}$ and Andrea Dall'Asta ${ }^{\mathrm{c}}$ \\ ${ }^{a}$ School of Engineering, University of Warwick, CV4 7AL, Coventry, United Kingdom. (Corresponding Author) \\ E-mail: freddi.fabio82@gmail.com; Phone: +39 3395214320. \\ ${ }^{\mathrm{b}}$ Department of Civil and Environmental Engineering, Rice University, 6100 Main Street, MS-318, Houston, \\ TX, USA 77005. E-mail: jamie.padgett@ rice.edu \\ ${ }^{\mathrm{c}}$ School of Architecture and Design, University of Camerino, Via della Rimembranza, 63100, Ascoli Piceno, \\ Italy. E-mail: andrea.dallasta@unicam.it
}

\begin{abstract}
Probabilistic methods to evaluate the seismic vulnerability of reinforced concrete (RC) frames are largely used in the context of performance based design and assessment, often describing the structural response using global engineering demand parameters $(E D P s)$ such as the maximum interstory drift. While such EDPs are able to synthetically describe the structural behavior, the use of local EDPs is necessary to provide a more realistic and thorough description of failure mechanisms of low-ductility frames lacking seismic details. The objective of this paper is to investigate viable probabilistic seismic demand models of local EDPs, which may be used in developing fragility curves for the assessment of the low-ductility RC frames. The present work explores adequate regression models, probability distributions and uncertainty variation of the demand models. In addition, the adequacy of several ground motion intensity measures $(I M s)$ to be used for predictive modeling of local EDPs is investigated. A realistic benchmark three-story RC frame representative of non-ductile buildings is used as a case study to identify key considerations.
\end{abstract}

Keywords Low-ductility Reinforced Concrete Frames, Fragility Curves, Probabilistic Seismic Demand Models, Local Engineering Demand Parameters, Intensity Measures

\section{Introduction}

Reinforced concrete (RC) buildings constructed before the introduction of advanced seismic design codes have suffered significant damage during past earthquakes due to a lack of adequate ductility. These structures represent one of the prevalent construction typologies in regions with high seismic activity worldwide. For example, as per the latest survey, experts estimate that in California alone approximately 20,000 non-ductile concrete buildings were constructed before the introduction of seismic design codes (Liel and Deierlein 2012). This highlights the need to develop reliable tools to assess the vulnerability of such structures.

Performance Based Earthquake Engineering (Cornell and Krawinkler 2000; Moehle and Deierlein 2004) has gained momentum to support seismic risk mitigation decision-making by disaggregating individual elements of the risk assessment. Seismic fragility curves are key elements of this process. Their efficacy hinges on the appropriate selection of a parameter used to describe the seismic intensity, denoted as the intensity measure (IM), and of a structural response parameter, denoted as the engineering demand parameter $(E D P)$. The probabilistic relationship constructed between the $I M$ and the EDP is used to evaluate the fragility, or conditional probability of exceeding a structural capacity limit given the level of $I M$. Fragility curves are widely employed in many fields such as seismic risk assessment, seismic retrofit prioritization and life cycle cost assessment. 
Incremental Dynamic Analysis (Vamvatsikos and Cornell 2002) is, amongst others, one of the most commonly used methods for generating samples of EDP-IM pairs necessary for fragility curve computation. In this procedure, the record-to-record variability is taken into account by selecting a bin of ground motion records that are amplitude scaled in order to describe the range of seismic intensities. Some limits of the method derive from the large amount of non-linear dynamic analyses required and, in some cases, from the excessive scaling factors that may be required to span the range of interest of the seismic intensity (Luco and Bazzurro 2007). Alternative methodologies which employ probabilistic seismic demand models (Cornell et al. 2002) can be used in order to overcome these limits. These models describe the variation of seismic demand by providing an analytical relationship between the $I M$ and the statistics of the EDPs, obtained by fitting, with a regression model, the outcomes of a reduced set of dynamic analyses. In this case the structure is subjected to a set of records with different $I M$ values providing a 'cloud' rather than a stripe of EDP-IM samples. When the intensity of the records is adequate to cause collapse of the structure, this technique permits the use of unscaled ground motions and a smaller set of records. Demand models are usually developed based on the assumption of a lognormal distribution of the demand for a given $I M$ value. Thus, the fitting problem consists of the definition of the two functions describing respectively the variation with the $I M$ of the logarithmic mean and standard deviation. Probabilistic models depend both on the monitored EDP and on the chosen ground motion $I M$.

Previous works on this topic have mainly focused on global response parameters, such as the top story displacement or the maximum interstory drift over the building height. These are synthetic parameters at structure-level and are employed as a proxy for inferring more local level (component-level) damage. Global EDPs may be adequate to describe the seismic response of structures designed by strength hierarchy rules, but may lead to an inadequate approximation in the vulnerability evaluation of low-ductility frames since in this case there is not a direct relation between local failure mechanisms and the global behavior (Freddi et al. 2013). This problem is also considered in international codes (FEMA 356; ACI 318; EC8) that require monitoring of global as well as local failure conditions in the deterministic seismic analysis of existing structures. However, in contemporary probabilistic analyses only global responses are traditionally monitored. This choice is driven in part by the high computational effort required in probabilistic analyses; however, in order to achieve an adequate description of the structural response and to maintain consistency between deterministic and probabilistic analyses, this issue should be addressed. Seismic vulnerability assessment of non-ductile structures should consider the fragility of multiple structural components which affect system level performance as well as losses, as suggested by Freddi et al. (2013), Bai et al. (2011) and Ghosh and Padgett (2011).

The objective of this paper is to investigate the viability of probabilistic seismic demand models in the description of the local EDPs response for the assessment of the low-ductility RC frames. This involves two main aspects: (1) the definition of adequate probabilistic models able to describe the different local failure mechanisms and (2) the sensitivity of the results with respect to different $I M$ choices. The derivation of local fragility curves for element or component level damage is enabled by the development of demand models for local EDPs.

In the presented study, several EDPs have been considered in order to monitor the most relevant failure modes in low-ductility RC frame buildings. Demand models of single 
structural components are developed for these EDPs, providing insight into the appropriate form of regression model. Additionally, hypothesis tests on the typical lognormal distribution of demand and variation of the demand uncertainty with the $I M$ are performed. In order to provide a comprehensive understanding of the issues concerning the ground motion intensity, several IMs proposed in literature (Padgett et al. 2008; Giovenale et al. 2004; Luco and Cornell 2007; Katsanos et al. 2010; Alavi and Krawinkler 2004) are analyzed and compared to identify which is the most appropriate to be used for predictive modeling of each local $E D P$ on the basis of their efficiency and sufficiency.

For case study purposes, a three-story moment resisting RC frame is adopted, which is representative of typical gravity load designed low-rise RC frames constructed in the Eastern and Central US. The case study frame was experimentally investigated extensively by Bracci et al. (1992a,b) and Aycardi et al. (1992), enabling validation of the finite element model and improved confidence in the global and local dynamic response estimates.

\section{Probabilistic Seismic Demand Analysis}

\section{General framework}

The probability of failure due to seismic events can be evaluated by the following expression:

$$
P[E D P>C]=\int_{0}^{\infty} G(\text { im }) f_{I M}(\text { im }) \operatorname{dim}
$$

based on the definition of the random variable $I M$ describing the earthquake intensity, whose variability is described by the probability density function $f_{I M}(\mathrm{im}) ; E D P$ and $C$ are random variables measuring the seismic demand and the seismic capacity of a structural component, respectively. The function $G(\mathrm{im})=P[E D P>C \mid i m]$ is the fragility curve providing the conditional probability of failure given the seismic intensity $\mathrm{im}$.

The $I M$ aims to synthesize the most important characteristic of the ground motion. Ideally, an appropriate $I M$ should be able to capture the amplitude, frequency content and duration properties of a ground motion which significantly affects the elastic and inelastic response of the structure. On the other hand, EDPs are response quantities used to predict structural damage and can generally be used to investigate a range of potential inadequacies of structures. Probabilistic seismic demand models, investigated in this paper, describe the variation of seismic demand by providing an analytical relationship between the $I M$ and the statistics of the EDPs allowing the definition of fragility curves by a closed form solution (Cornell et al. 2002).

\section{Ground motions and intensity measures}

The quality of an $I M$ is usually evaluated by the following properties: practicality, efficiency, sufficiency and hazard computability. Practicality measures the level of correlation between an $I M$ and the demand of the structural components (Padgett et al. 2008). An IM is efficient if it reduces the amount of dispersion in the estimated demand (Giovenale et al. 2004). Sufficiency of the $I M$ is the property that makes the structural response conditionally statistically independent of other ground motion characteristics, such as earthquake magnitude and source-to-site distance (Luco and Cornell 2007). Hazard computability refers to the effort required to assess the probabilistic seismic hazard or availability of hazard curves (Giovenale et al. 2004).

Many studies on different IMs have been performed in the recent years by considering 
their properties and their viability for demand response prediction. Results depend on the particular response parameter observed $(E D P)$ and on the characteristic of the considered structural system. For a general overview of the topic the reader can refer to Padgett et al. (2008), Luco and Cornell (2007), Katsanos et al. (2010) and Baker and Cornell (2005).

\section{Engineering Demand Parameters for low-ductility RC frames}

"Engineering Demand Parameters are structural response quantities that can be used to predict damage to structural and non structural component systems" (ATC 58). EDPs selected should correlate well with a measure of damage of the structure as well as with decision variables, such as, direct dollar losses and duration of downtime (Medina and Krawinkler 2003). Appropriate response indicators of the structure can be chosen based on the observation of failure modes highlighted in past earthquake events (Liel and Deierlein 2012). Global deformational parameters, such as the maximum story displacement and the maximum interstory drift are often used to estimate overall structural damage, while the maximum story acceleration is employed to evaluate building contents and non-structural damage. The use of global EDPs is suggested from some current guidelines (FEMA 356; HAZUS-MH 2.0) and several authors, e.g. Elwood and Moehle (2005), investigated the definition of capacity limits associated to global EDPs. Only a limited number of studies (i.e. Kazantsi and Vamvatsikos 2015) and guidelines (i.e. NIST 2010, FEMA-P58) recommend the use of story-level EDPs as a proxy for component damage. While global EDPs are structure-level parameters and local EDPs are component-level parameters, this type of EDPs based on story-level parameters can be considered as an intermediate-level EDPs. Although no detailed recommendations are provided, the use of local EDPs is also suggested if the damage of a single component is better correlated with such parameters. Depending on the type of component investigated, they may include, stresses and strain levels for steel and concrete fibers, forces and deformations, such as axial and shear forces, moments, curvatures and rotations. For some of these local parameters, capacity models have been largely investigated in the past and are extensively discussed in literature (Kappos et al 1999). In other cases (e.g. curvatures, moments, etc.), probabilistic models of the capacity could be obtained by propagating the uncertainties characterizing the mechanical behavior of the fibers (Tubaldi et al. 2012). However, further investigations may be required for the definition of adequate capacity models for local EDPs.

\section{Probabilistic Seismic Demand Model}

The use of probabilistic demand models generally permits the definition of fragility curves by a closed form solution (Cornell et al. 2002) and introduces an approximating function for the structural response. The relationship between the median structural demand, $E \hat{D} P$, and the $I M$ is usually approximated by a power law model (linear model in the log-log space):

$$
E \hat{D P}(\mathrm{im})=a \cdot \mathrm{im}^{b}
$$

where $a$ and $b$ are regression coefficients. In order to complete the probabilistic representation, the demand has traditionally been assumed as lognormally distributed with logarithmic standard deviation, $\beta_{E D P \mid I M}$ as reported in Fig. 1. The dispersion is expressed conditioned upon the seismic intensity to reflect the potential dependence of the variation in demand upon $\mathrm{im}$. However, homoscedasticity of the demand, i.e. $\beta_{E D P \mid I M}=\beta_{E D P}$, is often practically assumed. Under these assumptions along with a common assumption of the 
capacity as lognormally distributed, the probability that a value of the demand exceeds the capacity can be written as:

$$
G(i m)=1-\Phi\left(\frac{\ln \hat{C}-\ln E \hat{D} P(\text { im })}{\sqrt{\beta_{E D P \mid M}^{2}+\beta_{C}^{2}}}\right)
$$

where $\Phi(\cdot)$ is the standard normal cumulative distribution function and the capacity $C$ is a lognormal random variable, $\hat{C}$ is the median value and $\beta_{C}$ is the logarithmic standard deviation. Several authors have used this approach to develop fragility curves for RC buildings while using global EDPs (Hueste and Bai 2007) and homoscedasticity of the demand model was usually assumed (Bai et al. 2011; Celik and Ellingwood 2010). In order to conform with the homoscedasticity assumption, some authors (i.e. Jalayer 2003) recommend performing regression of the demand locally in the region of $I M$ values of interest. However, this procedure may be impractical when several EDPs or/and several limit states are considered at the same time. While considering maximum interstory drift as an EDP, other authors have found that the linear regression model in the log-log space was not accurate enough to represent the demand response. Ramamoorthy et al. (2006) developed fragility curves for low-rise RC buildings observing that a bilinear fit of the maximum interstory drift better represents the real behavior of the structure over the entire range of IM. Bai et al. (2011) developed fragility curves following the same approach. Tubaldi et al. (2016) investigated the use of demand models for the evaluation of earthquake-induced pounding of adjacent structures finding that bilinear demand models provide a more accurate description of the seismic demand due to its ability to account for the changes of the relative displacement demand due to structural yielding. Mackie and Stojadinovic (2003) defined demand models for bridges analyzing several EDPs and finding that a good fit of local EDPs such as material stress and strain can be obtained by adopting a bilinear regression.

Fig. 1 is illustrative and shows possible relations between $i m$ and the demand by employing (a) linear and (b) bilinear demand models in the log-log space. Linear and bilinear regression are achieved by minimizing the error between the mathematical model and the demand samples.
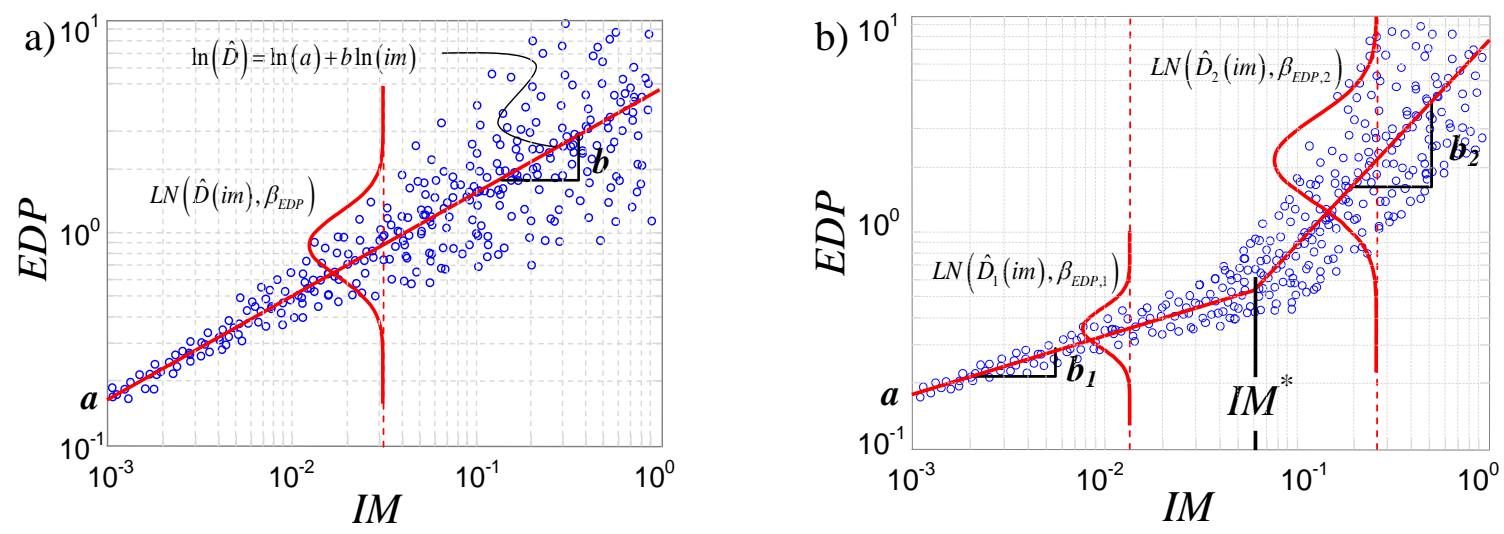

Fig. 1 Parameters of the: a) linear demand model, b) bilinear demand model in the log-log space

\section{Probabilistic Seismic Demand Models for Low-ductility RC Frames}

Existing RC frames differ in geometry and distribution of mechanical properties of structural components; however similar failure paths are generally observed in RC frames designed neglecting seismic actions. Extensive studies on the failure modes of RC frames, 
based experimental studies and on post earthquake reconnaissance are reported in literature (Elwood and Moehle 2005, Liel and Deierlein 2012). In order to evaluate the viability and the effectiveness of the use of specific forms of demand models, a case study reported in literature representative of low-ductility $\mathrm{RC}$ frames has been selected. The numerical model corresponds to the three-story $\mathrm{RC}$ moment resisting frame experimentally tested by Bracci et al. (1992a). The building has been designed for gravity loads only and without any seismic detailing, by applying the design rules existing before the introduction of modern seismic provisions. This case study has been selected because experimental results are available for a 1:3 reduced scale model of the frame and of its subassemblages (Bracci et al. 1992a,b; Aycardi et al. 1992). This allows an accurate validation of the finite element model at global as well as at local level and permits a reliable test of the probabilistic study. The validation of the model has been performed by comparing the displacement demand of a shaking table test performed with a PGA up to $0.3 \mathrm{~g}$ as well as by comparing the cyclic response of columns and subassemblages subjected to drift demand up to $4 \%$. Fig. 2 contains the general layout of the structure including the notation for beams (B), columns (C) and joints (J). A detailed description and validation of the numerical model is reported in the Appendix.

Table 1 reports the considered $I M S$ chosen to evaluate the probabilistic models of local EDPs. The IMs were selected among the most diffused and scalar IMs relatively easy to use and for which seismic hazard curves are either readily available or computable with a reasonable effort. The structure dependent $I M s$ are calculated with respect to the fundamental period of the structure $\left(\mathrm{T}_{1}=1.323 \mathrm{sec}\right)$ and by using a damping ratio of $5 \%$. The spectral acceleration predictor $\mathrm{S}_{\mathrm{aCM}}\left(\mathrm{T}_{1}\right)$ is the $I M$ proposed by Cordova et al. (2000) employing the coefficient suggested by Lin et al. (2011). For computing the inelastic spectral displacement, $\mathrm{S}_{\mathrm{di}}\left(\mathrm{T}_{1}\right)$ a non-linear single degree of freedom system with a 5\% post-yield hardening stiffness ratio has been employed. The period and the yield displacement of the bilinear system are estimated from the results of a non-linear static analysis as done in Tothong and Luco (2007). The use of vector valued IMs may be interesting for future investigation but are not considered in this study since they open a full range of alternative model forms, combinatorial expansion of the problem considering $I M$ pairs, and practical challenges in implementation.

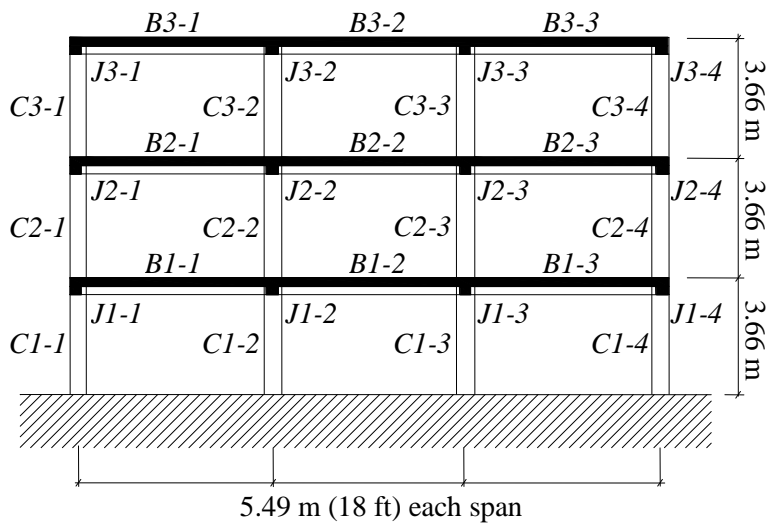

Fig. 2 General layout of the structure (Adopted from Bracci et al. 1992a)

The seismic response of the system is affected by uncertainties in the earthquake input (record-to-record variability), in the properties defining the system (model parameter uncertainty), and by lack of knowledge (epistemic uncertainty). However, only the effect of record-to-record variability is considered in this study since other sources of uncertainty (e.g. 
modeling uncertainty) may be considered a posteriori by means of default values of a dispersion measure assumed by data available in literature (Fajfar and Dolšek 2012). The uncertainty affecting the seismic input is taken into account by selecting a set of 240 natural records that reflect the variability in duration, frequency content, and other characteristics of the input expected to act on the system. This set has been selected by Baker et al. (2011) to be used in analyzing a variety of structural systems that would potentially be located in active seismic regions, and has a range of $I M$ characteristics as indicated in Table 1 . These records are representative of a wide range of variation in terms of source to site distance (R) (from 8.71 to $126.9 \mathrm{~km}$ ), soil characteristics $\left(\mathrm{V}_{\mathrm{s} 30}\right.$ spans from 203 to $2016.1 \mathrm{~m} / \mathrm{sec}$ ) and magnitude (M) (from 5.3 to 7.9). Pulse like records are not included.

In order to investigate all of the possible failure modes, 11 EDPs are considered as shown in Table 2. In addition to the local level EDPs, intermediate EDPs and the commonly used global EDPs have been included in the list. Demand models for all of the considered IM-EDP pairs are developed by using the dynamic responses from 240 time history analyses in what is often termed a 'cloud analysis'. Demand models are developed for all of the structural components of the frame reported in Fig. 2. The shear force $\left(\mathrm{V}_{\max }\right)$ is evaluated in the 21 beams and columns; strains $\left(\varepsilon_{\mathrm{s}, \max }, \varepsilon_{\mathrm{c}, \max }\right)$, curvature $\left(\phi_{\max }\right)$ and moment $\left(\mathrm{M}_{\max }\right)$ are considered in both the ends of each structural element (42 components); joint stresses $\left(\sigma_{j}\right.$,tens,max, $\left.\sigma_{\mathrm{j}, \text { compr,max }}\right)$ are considered in all the joints (12 components); interstory drift $\left(\theta_{\mathrm{i}, \mathrm{max}}\right)$, story velocity $\left(\mathrm{St}_{\mathrm{V}} \mathrm{Vel}_{\mathrm{i}, \max }\right)$ and story acceleration $\left(\mathrm{St}_{\mathrm{A}} \mathrm{Acc_{i, \operatorname {max } } )}\right.$ are evaluated at each story of the frame (3 components each). The base shear is defined by a single component. Overall, considering all of the EDP-IM pairs, 2453 probabilistic seismic demand models have been developed. Only the demand models using $S_{a}\left(T_{1}\right)$ are shown as examples to explore the regression form, however, all EDP-IM pairs were evaluated confirming that the behavior in terms of viability of linear versus bilinear regression (in log-log space) is consistent across all IMs.

Fig. 3 illustrates the demand models constructed in the log-log space for four different among global and intermediate EDPs, including (a) interstory drift at the $1^{\text {st }}$ level $\left(\theta_{1}\right)$, (b) top story velocity, (c) top story acceleration, and $(\mathrm{d})$ base shear $\left(\mathrm{V}_{\mathrm{b}}\right)$. The results reveal that linear regression of the structural demands relative to $S_{a}\left(T_{1}\right)$ provides a good fit for the drift, velocity, and acceleration responses. In contrast, bilinear regression is needed to obtain a better fit of the analyses results for the base shear where, after the elastic limit of the force is exceeded, the slope of the regression is lower capturing the post yielding behavior of the structure. In addition, it can be observed that for the interstory drift at the $1^{\text {st }}$ level $\left(\theta_{1}\right)$ in Fig. 3 (a), the dispersion increases with increasing $I M$ values; differently, for the base shear $\left(\mathrm{V}_{\mathrm{b}}\right)$ in Fig. 3 (d) the dispersion is reduced as $I M$ increases. Top story velocity and top story acceleration, respectively, in Fig. 3 (b) and (c) show a lower variation of the dispersion with increasing $I M$ values.

Table 1 Intensity Measures (IMs)

\begin{tabular}{lllll}
\hline$I M s$ & Description & Formula & Units & Range \\
\hline \multicolumn{4}{r}{} & \multicolumn{4}{l}{ Structure Dependent $I M s$} \\
\hline $\mathrm{S}_{\mathrm{a}}$ & Spectral Acceleration at $\mathrm{T}_{1}$ & - & $\mathrm{g}$ & $0.0051-0.9806$ \\
$\mathrm{~S}_{\mathrm{v}}$ & Spectral Velocity at $\mathrm{T}_{1}$ & - & $\mathrm{cm} / \mathrm{sec}$ & $1.897-204.97$ \\
$\mathrm{~S}_{\mathrm{d}}$ & Spectral Displacement at $\mathrm{T}_{1}$ & - & $\mathrm{cm}$ & $0.218-42.40$
\end{tabular}




\begin{tabular}{lllll}
$\mathrm{S}_{\mathrm{di}}$ & Inelastic Spectral Displacement at $\mathrm{T}_{1}$ & - & $\mathrm{cm}$ & $0.218-48.32$ \\
$\mathrm{~S}_{\mathrm{aC}}$ & Sa Predictor (Cordova et al.) & $S_{a}\left(T_{1}\right)\left\{\frac{S_{a}\left(2 T_{1}\right)}{S_{a}\left(T_{1}\right)}\right\}^{0.5}$ & $\mathrm{~g}$ & $0.0013-0.259$ \\
$\mathrm{~S}_{\mathrm{aCM}}$ & Sa Predictor (Cordova et al. modified) & $S_{a}\left(T_{1}\right)\left\{\frac{S_{a}\left(1.5 T_{1}\right)}{S_{a}\left(T_{1}\right)}\right\}^{0.5}$ & $\mathrm{~g}$ & $0.0013-0.281$ \\
& \multicolumn{1}{c}{ Structure Independent $I M s$} & & \\
\hline & & - & $\mathrm{g}$ & $0.019-1.068$ \\
\hline PGA & Peak Ground Acceleration & - & $\mathrm{cm} / \mathrm{sec}$ & $1.261-130.28$ \\
PGV & Peak Ground Velocity & - & $\mathrm{cm}$ & $0.188-119.70$ \\
PGD & Peak Ground Displacement & - & $\mathrm{g}$ & $0.041-2.136$ \\
$\mathrm{~S}_{\mathrm{a}-02 \mathrm{~s}}$ & Spectral Acceleration at $0.2 \mathrm{sec}$ & - & $\mathrm{g}$ & $0.0121-1.3925$ \\
$\mathrm{~S}_{\mathrm{a}-1 \mathrm{~s}}$ & Spectral Acceleration at $1 \mathrm{sec}$ & &
\end{tabular}

Table 2 Engineering Demand Parameters $(E D P s)$

\begin{tabular}{|c|c|c|c|}
\hline$E D P$ & Description & Performance characteristic & Units \\
\hline \multicolumn{4}{|c|}{ Local EDPs } \\
\hline$\varepsilon_{\mathrm{s}, \max }$ & Steel strain - longitudinal & Flexural and axial behavior & - \\
\hline$\varepsilon_{\mathrm{c}, \max }$ & Concrete strain - longitudinal fibers & Flexural and axial behavior & - \\
\hline$\phi_{\max }$ & Curvature & Flexural behavior & $1 / \mathrm{m}$ \\
\hline$\sigma_{\mathrm{j}, \text { tens,max }}$ & Joint tensile stress & Joint behavior & $\mathrm{kN} / \mathrm{m}^{2}$ \\
\hline$\sigma_{\mathrm{j}, \mathrm{compr}, \max }$ & Joint compressive stress & Joint behavior & $\mathrm{kN} / \mathrm{m}^{2}$ \\
\hline $\mathrm{V}_{\max }$ & Shear & Shear resistance & $\mathrm{kN}$ \\
\hline $\mathrm{M}_{\max }$ & Moment & Flexural resistance & $\mathrm{kNm}$ \\
\hline \multicolumn{4}{|c|}{ Global and Intermediate EDPs } \\
\hline $\mathrm{V}_{\mathrm{b}, \max }$ & Base shear & Structural behavior & $\mathrm{kN}$ \\
\hline$\theta_{i, \max }$ & Interstory drift & Structural and non-structural behavior & $\mathrm{rad}$ \\
\hline St.Vel $_{i, \max }$ & Story velocity & Contents and non-structural behavior & $\mathrm{m} / \mathrm{sec}$ \\
\hline St.Acc & Story acceleration & Contents and non-structural behavior & $\mathrm{m} / \mathrm{sec}^{2}$ \\
\hline
\end{tabular}

Demand models for local EDPs have been developed for all critical sections of the structure. For most of the sections, which exhibit significant non-linear behavior, a bilinear regression is indispensable to adequately represent the demand. Fig. 4 to 7 report the linear vs bilinear regression model for local EDPs. The EDPs reported are: Fig. 4 (a) curvature ( $\left.\phi_{\max }\right)$ and (b) bending moment $\left(\mathrm{M}_{\max }\right)$ for upper column C1-1; Fig. 5 (a) steel strain in longitudinal reinforcements $\left(\varepsilon_{\mathrm{s}, \max }\right)$ and (b) concrete strain in the maximum compressed fiber $\left(\varepsilon_{\mathrm{c}, \max }\right)$ for upper column C1-1; Fig. 6 (a) shear force $\left(\mathrm{V}_{\max }\right)$ of column $\mathrm{C1}-1$ and (b) shear force $\left(\mathrm{V}_{\max }\right)$ of beam B1-1; Fig. 7 (a) concrete tensile $\left(\sigma_{\mathrm{j}, \text { tens,max }}\right)$ and (b) compressive stress $\left(\sigma_{\mathrm{j}, \text { comp,max }}\right)$ of joint J1-1. Steel and concrete maximum strains are strictly correlated with the sectional curvature and thus their behavior is comparable. For these EDPs, bilinear regressions of the demand are found to be the best fits reflecting typical stress-strain bilinear behavior of the materials and typical moment-curvature bilinear behavior for sections. For deformation-based EDPs (i.e. $\left.\phi_{\max }, \varepsilon_{\mathrm{s}, \max }, \varepsilon_{\mathrm{c}, \max }\right)$ the slope of the second segment of the bilinear regression is higher, while for force-based EDPs (i.e. $\mathrm{M}_{\max }, \mathrm{V}_{\max }, \sigma_{\mathrm{j}, \text { tens,max }}, \sigma_{\mathrm{j}, \text { comp,max }}$ ) there is the opposite situation capturing the post yielding behavior of the components. In addition, it can be observed that with deformation-based EDPs the dispersion increases with increasing IM values; differently with force-based $E D P s$ the dispersion reduces with increasing $I M$ values. 
This different behavior, observed also while looking at global and intermediate EDPs, is a consequence of the fact that for deformation-based EDPs, in the post-elastic field a small variation of the force causes a high variation of the displacement. With force-based EDPs the dispersion is reduced as a consequence of the upper bound that characterizes this type of $E D P$. In particular, it is possible to observe that for deformation-based EDPs the higher increase in dispersion corresponds with the breakpoint of the bilinear regression. Additional considerations regarding the variation of the dispersions are reported in Section 5.
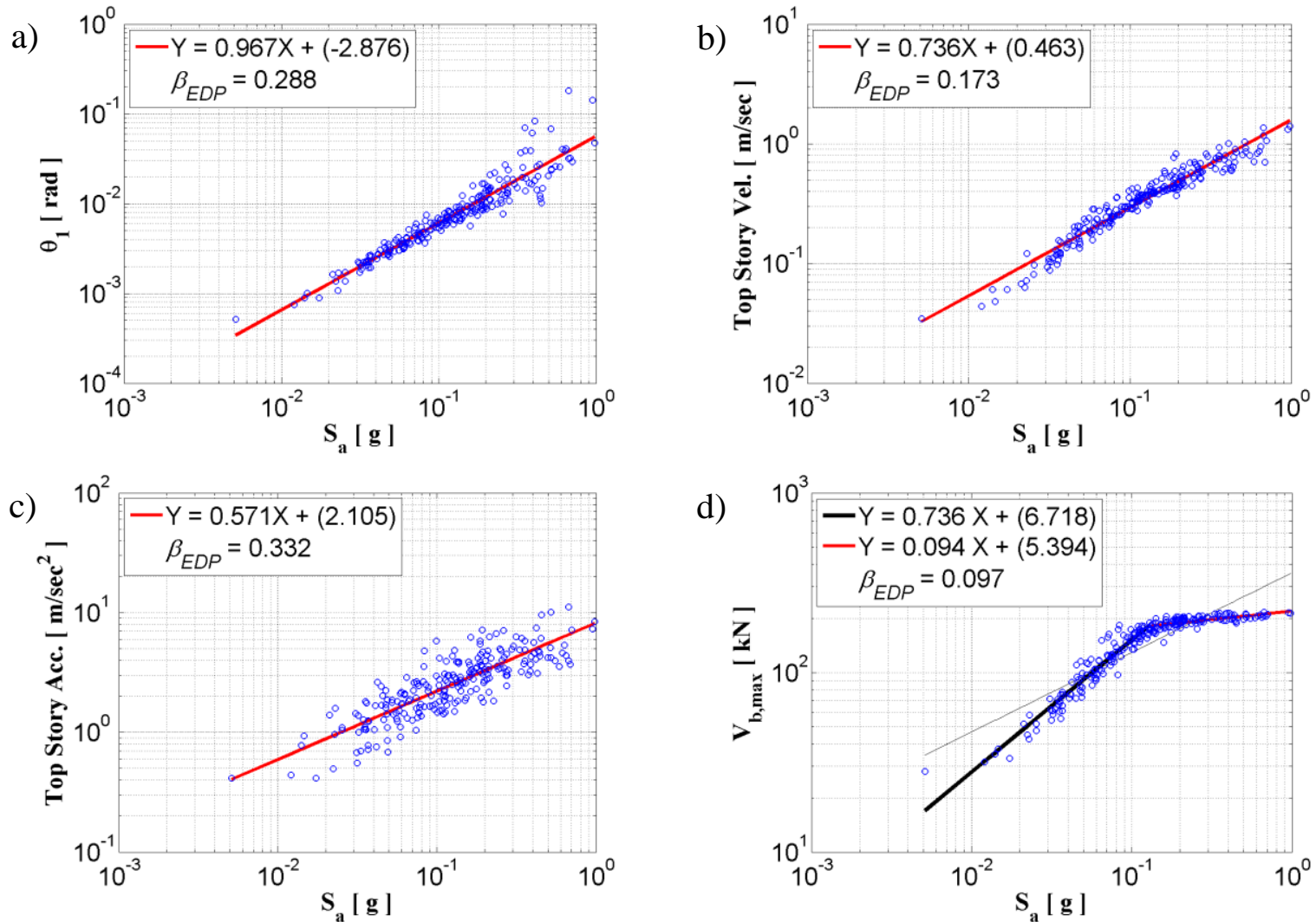

Fig. 3 Demand models for global and intermediate EDPs: a) Interstory drifts for $1^{\text {th }}$ story, b) Top story velocity, c) Top story acceleration, d) Base shear. $S_{a}\left(T_{1}\right)$ is used as the $I M$ for illustration
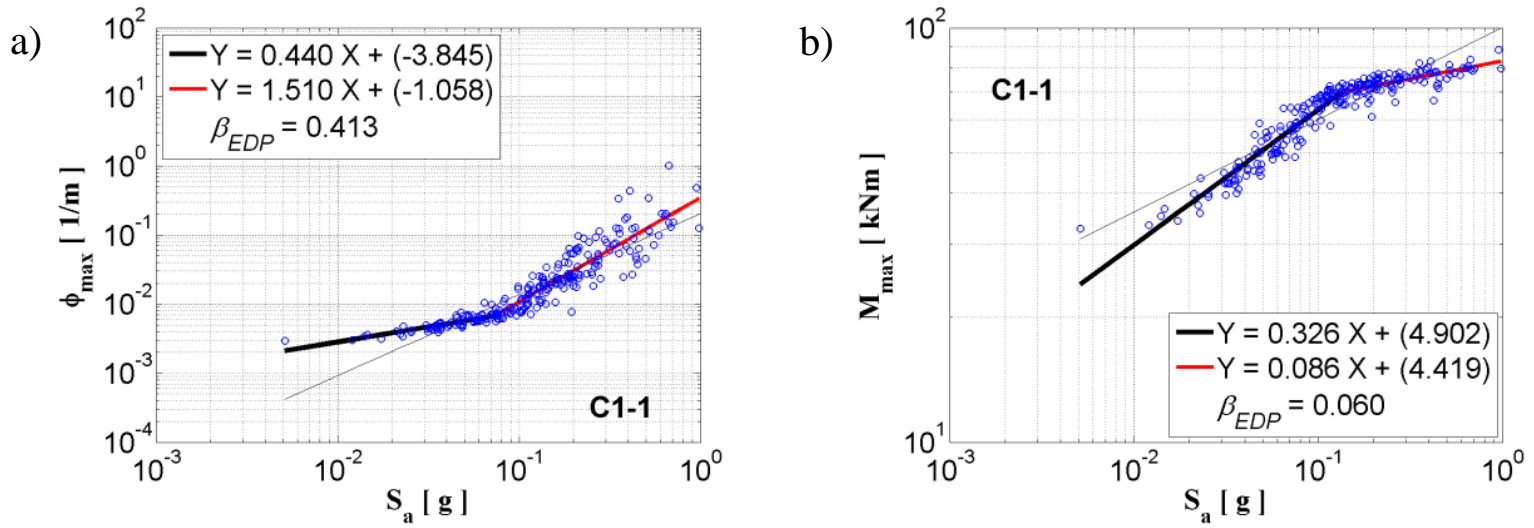

Fig. 4 Demand models comparing linear and bilinear regression for local EDPs: a) Curvature and b) Bending moment in the upper section of column $\mathrm{C} 1-1 . \mathrm{S}_{\mathrm{a}}\left(\mathrm{T}_{1}\right)$ is used as the $I M$ for illustration 

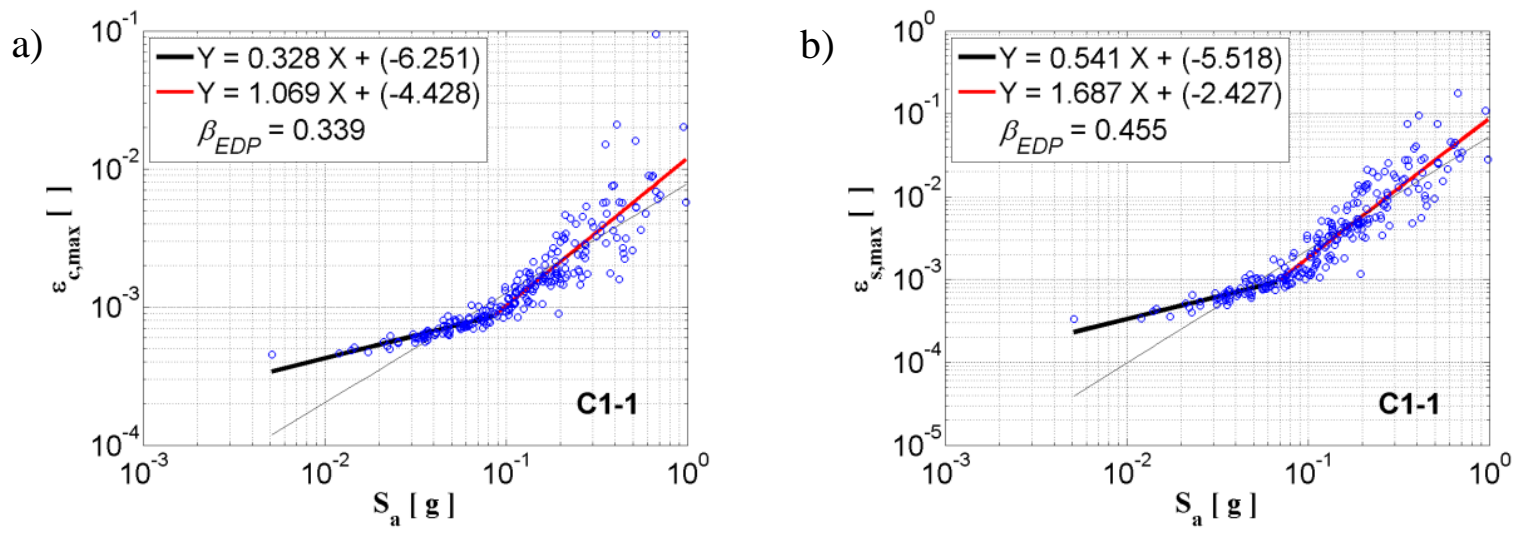

Fig. 5 Demand models comparing linear and bilinear regression for local EDPs: a) Concrete strain and b) Steel strain in the upper section of column C1-1. $\mathrm{S}_{\mathrm{a}}\left(\mathrm{T}_{1}\right)$ is used as the $I M$ for illustration
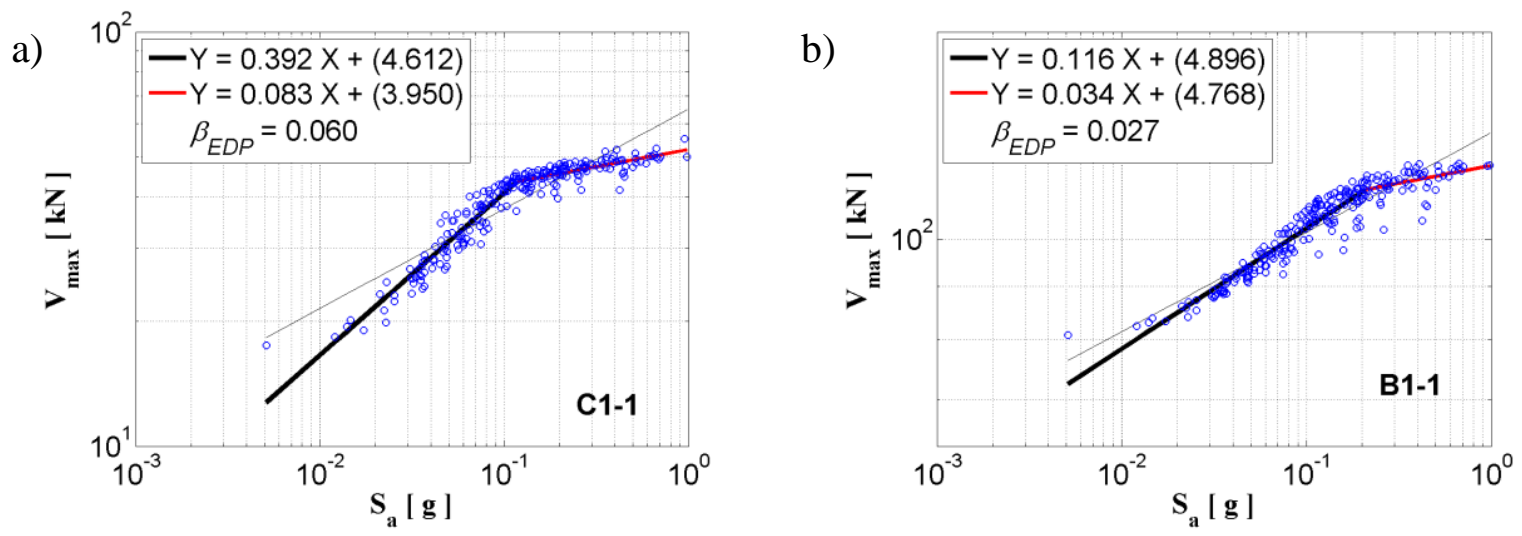

Fig. 6 Demand models comparing linear and bilinear regression for local EDPs: a) Shear force in the column C1-1, b) Shear force in the beam B1-1. $\mathrm{S}_{\mathrm{a}}\left(\mathrm{T}_{1}\right)$ is used as the $I M$ for illustration
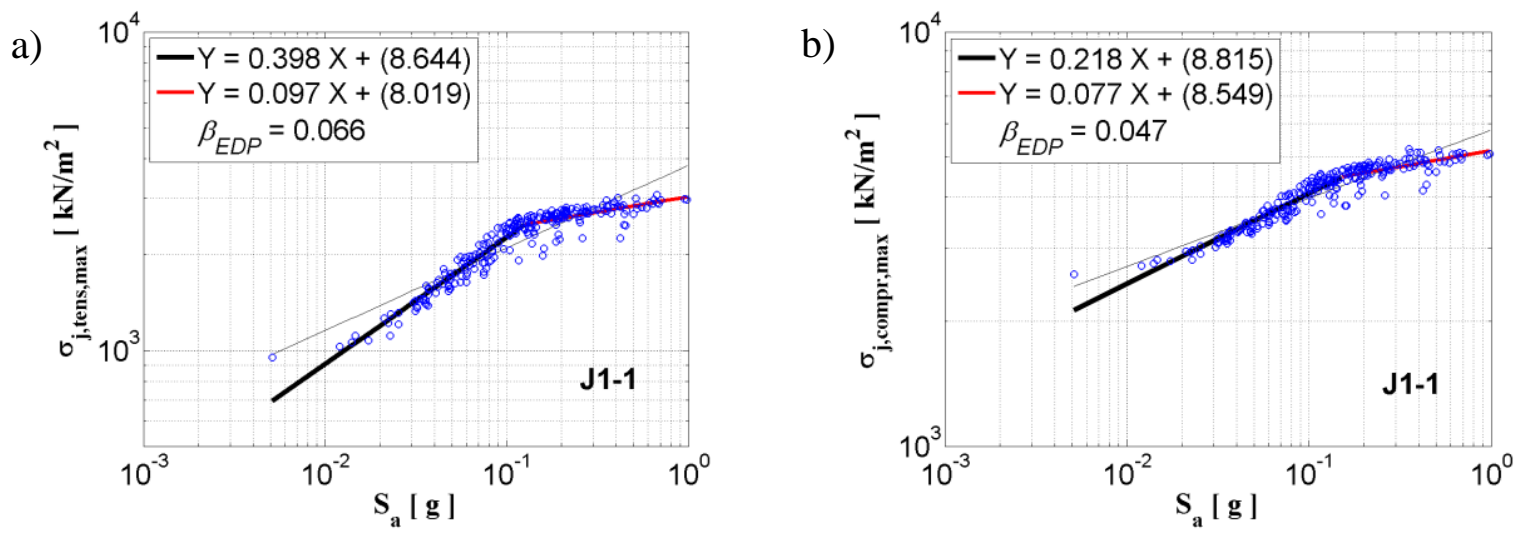

Fig. 7 Demand models comparing linear and bilinear regression for local EDPs: a) Tensile stress and b) Compressive stress in the joint $\mathrm{J} 1-1 . \mathrm{S}_{\mathrm{a}}\left(\mathrm{T}_{1}\right)$ is used as the $I M$ for illustration

The comparison of model form for all EDPs and additional tests that focus on the model skills evaluation reveal that when local EDPs are used, bilinear regressions are indispensable to obtain adequate demand models. Since in many cases the vulnerability evaluations focus on the worst damage condition over the entire building, evaluation of the regression model has been performed also considering the maximum value of each EDP among all the structural components. This study confirms the results obtained for the single component. 


\section{Intensity measure comparison for different EDPs}

Having identified the regression model form for each $E D P$, a comparison of alternative $I M s$ is conducted. Conditions of practicality, sufficiency, efficiency and hazard computability are evaluated. All of the IM-EDP pairs evaluated in this paper are considered practical and amongst others, the efficiency is assumed as the main decision criteria (Padgett et al. 2008). The properties of the IMs are derived for each considered EDP and for each component of the structure. Successively, average values for each EDP among the components and average values among EDPs and components are derived as synthetic parameters to rapidly screen the overall ability of the $I M$ for the entire structure.

\subsection{Efficiency}

Efficiency indicates the amount of variability of an $E D P$ given an $I M$ and is quantified by the dispersion, $\beta_{E D P \mid M}$ (Giovenale et al. 2004). Results to indentify the 'best' $I M$ based on reduced $\beta_{E D P \mid M}$ are reported in Table 3 .

Table 3 Mean values of $\beta_{E D P \mid I M}$ across all components for each $E D P$ used to evaluate $I M$ efficiency

\begin{tabular}{|c|c|c|c|c|c|c|c|c|c|c|c|c|}
\hline & & \multicolumn{6}{|c|}{ Structure dependent $I M s$} & \multicolumn{5}{|c|}{ Structure independent $I M s$} \\
\hline & n.comp. & $\mathrm{S}_{\mathrm{a}}$ & $\mathrm{S}_{\mathrm{v}}$ & $S_{d}$ & $\mathrm{~S}_{\mathrm{di}}$ & $\mathrm{S}_{\mathrm{aC}}$ & $\mathrm{S}_{\mathrm{aCM}}$ & PGA & PGV & PGD & $\mathrm{S}_{\mathrm{a}-02 \mathrm{~s}}$ & $S_{\mathrm{a}-1 \mathrm{~s}}$ \\
\hline \multicolumn{13}{|c|}{ Local EDPs } \\
\hline$\varepsilon_{\mathrm{s}, \max }$ & 42 & 0.30 & 0.32 & 0.30 & 0.29 & 0.33 & 0.32 & 0.62 & 0.39 & 0.52 & 0.69 & 0.41 \\
\hline$\varepsilon_{c, \max }$ & 42 & 0.26 & 0.28 & 0.26 & 0.25 & 0.28 & 0.27 & 0.54 & 0.34 & 0.46 & 0.61 & 0.36 \\
\hline$\phi_{\max }$ & 42 & 0.17 & 0.18 & 0.17 & 0.17 & 0.20 & 0.19 & 0.38 & 0.24 & 0.32 & 0.42 & 0.25 \\
\hline$\sigma_{\mathrm{j}, \text { tens,max }}$ & 12 & 0.05 & 0.06 & 0.05 & 0.05 & 0.08 & 0.07 & 0.16 & 0.10 & 0.12 & 0.17 & 0.10 \\
\hline$\sigma_{\mathrm{j}, \mathrm{compr}, \max }$ & 12 & 0.06 & 0.07 & 0.06 & 0.06 & 0.10 & 0.09 & 0.21 & 0.13 & 0.16 & 0.22 & 0.12 \\
\hline $\mathrm{V}_{\max }$ & 21 & 0.03 & 0.03 & 0.03 & 0.03 & 0.04 & 0.04 & 0.04 & 0.03 & 0.05 & 0.05 & 0.03 \\
\hline$M_{\max }$ & 42 & 0.20 & 0.21 & 0.20 & 0.20 & 0.24 & 0.22 & 0.44 & 0.28 & 0.37 & 0.49 & 0.29 \\
\hline \multicolumn{13}{|c|}{ Global and Intermediate EDPs } \\
\hline$\overline{V_{b, \max }}$ & 1 & 0.10 & 0.10 & 0.10 & 0.10 & 0.15 & 0.13 & 0.34 & 0.21 & 0.25 & 0.36 & 0.19 \\
\hline$\theta_{\mathrm{i}, \max }$ & 3 & 0.24 & 0.27 & 0.24 & 0.23 & 0.29 & 0.27 & 0.60 & 0.36 & 0.49 & 0.67 & 0.36 \\
\hline St.Vel & 3 & 0.22 & 0.18 & 0.22 & 0.21 & 0.28 & 0.26 & 0.44 & 0.28 & 0.43 & 0.51 & 0.28 \\
\hline St.Acc & 3 & 0.42 & 0.38 & 0.42 & 0.43 & 0.46 & 0.45 & 0.21 & 0.38 & 0.50 & 0.29 & 0.39 \\
\hline Average & 223 & 0.20 & 0.21 & 0.20 & 0.19 & 0.23 & 0.22 & 0.42 & 0.27 & 0.35 & 0.47 & 0.28 \\
\hline
\end{tabular}

These results show that structure dependent $I M s$ tend to be much more efficient for all the considered EDPs relative to the structure independent IMs. Among the structure independent $I M s, \mathrm{~S}_{\mathrm{a}-1 \mathrm{~s}}$ and PGV have the lowest dispersions. The efficiency of $\mathrm{S}_{\mathrm{a}-1 \mathrm{~s}}$ can be attributed to the closeness in fundamental period of the structure $\left(\mathrm{T}_{1}=1.323 \mathrm{~s}\right)$ to the fixed $1 \mathrm{~s}$ period considered in the $I M$. Differently, PGV is recognized as an efficient $I M$ for energy-based response parameters and this finding is consistent with past studies relevant to global EDPs (Conte et al. 2003). Among the structure dependent $I M s, \mathrm{~S}_{\mathrm{di}}\left(\mathrm{T}_{1}\right), \mathrm{S}_{\mathrm{a}}\left(\mathrm{T}_{1}\right)$ and $\mathrm{S}_{\mathrm{d}}\left(\mathrm{T}_{1}\right)$ are found to be the 'best' IMs consistent with previously obtained results from studies on framed structures and bridges (Mackie and Stojadinovic 2003; Tothong and Luco 2007) while considering global EDPs. The dispersions of $\mathrm{S}_{\mathrm{v}}\left(\mathrm{T}_{1}\right), \mathrm{S}_{\mathrm{aCM}}\left(\mathrm{T}_{1}\right)$ and $\mathrm{S}_{\mathrm{aC}}\left(\mathrm{T}_{1}\right)$ are slightly larger, but these $I M s$ are still relatively efficient, in particular with respect to the structure independent IMs. The optimal $I M$ in terms of efficiency does not tend to show dependence upon EDP of interest, and consistent results can be observed looking at each EDP independently. The story 
acceleration is the only exception. In fact, with this EDP there is no substantial difference between the efficiency of structure dependent and structure independent IMs.

\subsection{Sufficiency}

The IMs are evaluated for sufficiency in terms of conditional statistical independence of the response from magnitude (M) and distance (R) (Padgett et al. 2008; Luco and Cornell 2007). It is acknowledged that sufficiency with respect to other characteristics such as 'epsilon' (Baker and Cornell 2005) or duration is also desirable, but these extended tests are beyond the scope of the current study. Residuals from the demand models are considered in a linear regression with $\mathrm{M}$ and $\mathrm{R}$. Hypothesis tests of residual independence from $\mathrm{M}$ or $\mathrm{R}$ are conducted resulting in p-values (Hines et al. 2003) used to assess the sufficiency. The p-value is defined as the probability of rejecting the null hypothesis in an analysis of variance, which states that the coefficient of regression is zero. Smaller p-values indicate stronger evidence for rejecting the null hypothesis and evidence of insufficient $I M$ (Padgett et al. 2008).

Tables 4 and 5 show the results for sufficiency hypothesis tests for $\mathrm{M}$ and $\mathrm{R}$, respectively. In particular, the fraction of components where the sufficiency hypothesis test is satisfied is reported for all of the considered EDPs and IMs. P-values lower than the assumed cut off value of 0.025 (Hines et al. 2003) indicate that the sufficiency hypothesis test is rejected. Consistent results are obtained using different values of the statistical significance level. Among all of the IM-EDP pairs, PGA and $\mathrm{S}_{\mathrm{a}-02 \mathrm{~s}}$ are found to be insufficient with respect to magnitude, while PGD is found to be insufficient with respect to distance. PGV is the IM that best satisfies the sufficiency hypothesis test with respect to both $\mathrm{M}$ and $\mathrm{R}$ while all the others $I M s$ are considered equally sufficient. It is interesting to observe that in most of the cases, story acceleration presents a lack of sufficiency with respect to the distance.

Table 4 Check of the sufficiency hypothesis test with respect magnitude (M): Fraction of components where it is satisfied (cut off of the p-value equal to 0.025)

\begin{tabular}{|c|c|c|c|c|c|c|c|c|c|c|c|c|}
\hline & & \multicolumn{6}{|c|}{ Structure dependent $I M s$} & \multicolumn{5}{|c|}{ Structure independent $I M s$} \\
\hline & n.comp. & $\mathrm{S}_{\mathrm{a}}$ & $\mathrm{S}_{\mathrm{v}}$ & $S_{d}$ & $\mathrm{~S}_{\mathrm{di}}$ & $\mathrm{S}_{\mathrm{aC}}$ & $\mathrm{S}_{\mathrm{aCM}}$ & PGA & PGV & PGD & $\mathrm{S}_{\mathrm{a}-02 \mathrm{~s}}$ & $\mathrm{~S}_{\mathrm{a}-1 \mathrm{~s}}$ \\
\hline \multicolumn{13}{|c|}{ Local EDPs } \\
\hline$\varepsilon_{\mathrm{s}, \max }$ & 42 & 0.95 & 0.90 & 0.95 & 0.98 & 1.00 & 0.95 & 0.12 & 0.98 & 0.98 & 0.05 & 0.83 \\
\hline$\varepsilon_{\mathrm{c}, \max }$ & 42 & 0.90 & 0.86 & 0.90 & 0.95 & 0.98 & 0.95 & 0.12 & 0.95 & 1.00 & 0.00 & 0.79 \\
\hline$\phi_{\max }$ & 42 & 0.98 & 0.88 & 0.95 & 1.00 & 1.00 & 0.95 & 0.07 & 1.00 & 0.98 & 0.02 & 0.81 \\
\hline$\sigma_{\mathrm{j}, \text { tens, } \max }$ & 12 & 0.95 & 1.00 & 0.95 & 1.00 & 1.00 & 1.00 & 0.00 & 1.00 & 0.95 & 0.00 & 0.90 \\
\hline$\sigma_{\mathrm{j}, \mathrm{compr}, \max }$ & 12 & 1.00 & 1.00 & 1.00 & 1.00 & 1.00 & 1.00 & 0.00 & 1.00 & 1.00 & 0.00 & 1.00 \\
\hline $\mathrm{V}_{\max }$ & 21 & 0.92 & 0.92 & 0.92 & 1.00 & 1.00 & 1.00 & 0.00 & 0.92 & 0.83 & 0.00 & 0.83 \\
\hline$M_{\max }$ & 42 & 0.95 & 0.95 & 0.95 & 1.00 & 0.98 & 0.95 & 0.02 & 0.95 & 0.98 & 0.02 & 0.86 \\
\hline \multicolumn{13}{|c|}{ Global and Intermediate $E D P S$} \\
\hline$\overline{\mathrm{V}_{\mathrm{b}, \max }}$ & 1 & 1.00 & 1.00 & 1.00 & 1.00 & 1.00 & 1.00 & 0.00 & 1.00 & 1.00 & 0.00 & 1.00 \\
\hline$\theta_{\mathrm{i}, \max }$ & 3 & 1.00 & 0.67 & 1.00 & 1.00 & 1.00 & 1.00 & 0.00 & 1.00 & 0.67 & 0.00 & 0.33 \\
\hline St.Vel & 3 & 1.00 & 1.00 & 1.00 & 1.00 & 1.00 & 1.00 & 0.00 & 0.33 & 0.33 & 0.00 & 1.00 \\
\hline St.Acc & 3 & 1.00 & 1.00 & 1.00 & 1.00 & 1.00 & 1.00 & 0.67 & 1.00 & 1.00 & 0.67 & 1.00 \\
\hline Average & 223 & 0.95 & 0.91 & 0.94 & 0.99 & 0.99 & 0.96 & 0.07 & 0.96 & 0.95 & $\mathbf{0 . 0 3}$ & 0.84 \\
\hline
\end{tabular}

Note: Bold value indicates insufficient $I M$. 
Table 5 Check of the sufficiency hypothesis test with respect distance (R): Fraction of components where it is satisfied (cut off of the p-value equal to 0.025)

\begin{tabular}{|c|c|c|c|c|c|c|c|c|c|c|c|c|}
\hline & & \multicolumn{6}{|c|}{ Structure dependent $I M s$} & \multicolumn{5}{|c|}{ Structure independent $I M s$} \\
\hline & n.comp. & $S_{a}$ & $S_{\mathrm{v}}$ & $S_{d}$ & $\mathrm{~S}_{\mathrm{di}}$ & $\mathrm{S}_{\mathrm{aC}}$ & $\mathrm{S}_{\mathrm{aCM}}$ & PGA & PGV & PGD & $S_{a-02 s}$ & $S_{\mathrm{a}-1 \mathrm{~s}}$ \\
\hline \multicolumn{13}{|c|}{ Local EDPs } \\
\hline$\varepsilon_{\mathrm{s}, \max }$ & 42 & 0.86 & 0.81 & 0.86 & 0.76 & 0.76 & 0.74 & 1.00 & 0.93 & 0.10 & 1.00 & 1.00 \\
\hline$\varepsilon_{c, \max }$ & 42 & 0.81 & 0.81 & 0.81 & 0.76 & 0.74 & 0.69 & 1.00 & 0.95 & 0.12 & 1.00 & 0.95 \\
\hline$\phi_{\max }$ & 42 & 0.81 & 0.62 & 0.79 & 0.79 & 0.79 & 0.67 & 1.00 & 0.95 & 0.24 & 1.00 & 0.98 \\
\hline$\sigma_{j, \text { tens,max }}$ & 12 & 1.00 & 0.52 & 1.00 & 1.00 & 0.81 & 0.71 & 1.00 & 0.95 & 0.19 & 1.00 & 1.00 \\
\hline$\sigma_{\mathrm{j}, \mathrm{compr}, \mathrm{ma}}$ & 12 & 0.75 & 0.33 & 0.75 & 0.83 & 0.83 & 0.67 & 1.00 & 0.83 & 0.33 & 1.00 & 0.92 \\
\hline $\mathrm{V}_{\max }$ & 21 & 1.00 & 0.92 & 1.00 & 0.58 & 0.75 & 0.67 & 0.92 & 1.00 & 0.08 & 1.00 & 1.00 \\
\hline $\mathrm{M}_{\max }$ & 42 & 0.76 & 0.64 & 0.76 & 0.74 & 0.76 & 0.67 & 1.00 & 0.95 & 0.14 & 1.00 & 1.00 \\
\hline \multicolumn{13}{|c|}{ Global and Intermediate $E D P s$} \\
\hline$\overline{V_{b, \max }}$ & 1 & 1.00 & 1.00 & 1.00 & 1.00 & 1.00 & 1.00 & 1.00 & 1.00 & 0.00 & 1.00 & 1.00 \\
\hline$\theta_{\mathrm{i}, \max }$ & 3 & 1.00 & 1.00 & 1.00 & 1.00 & 1.00 & 1.00 & 1.00 & 1.00 & 0.33 & 1.00 & 1.00 \\
\hline St.Vel & 3 & 1.00 & 0.67 & 1.00 & 0.33 & 0.67 & 0.67 & 0.67 & 1.00 & 0.00 & 1.00 & 1.00 \\
\hline St.Acc & 3 & 0.00 & 0.00 & 0.00 & 0.00 & 0.00 & 0.00 & 1.00 & 0.00 & 0.00 & 1.00 & 0.00 \\
\hline Average & 223 & 0.83 & 0.70 & 0.83 & 0.75 & 0.76 & 0.68 & 0.99 & 0.93 & 0.15 & 1.00 & 0.97 \\
\hline
\end{tabular}

Note: Bold value indicates insufficient $I M$.

\subsection{Hazard computability}

Among the IMs considered, hazard information is readily available across the United States for PGA, PGV, PGD, and specific spectral quantities corresponding to $0.2 \mathrm{sec}$ and 1.0 sec $\left(\mathrm{S}_{\mathrm{a}-02 \mathrm{~s}}\right.$ and $\left.\mathrm{S}_{\mathrm{a}-1 \mathrm{~s}}\right)$, from such entities as the US Geological Survey (http://earthquake.usgs.gov/). For the structure dependent IMs considered in this paper, hazard curves can be approximated with a reasonable level of effort except for the inelastic spectral displacement for which attenuation relationships are usually not available.

\section{Assessment of demand variation}

This section investigates two simplifying assumptions usually made while employing probabilistic seismic demand models. In particular, the variation of the dispersion of the demand with increasing ground motion intensity and its probability distribution often adopted as lognormal are explored.

\subsection{Homoscedasticity Assumption}

Homoscedasticity of the demand (i.e. $\beta_{E D P \mid I M}=\beta_{E D P}$ ) is often assumed as a simplification of the probabilistic seismic demand model. In order to verify the validity of this assumption for the EDPs and IMs considered in this study, logarithmic standard deviation $\beta_{E D P}$ is calculated for different intervals of the $I M$ value. The full range of each $I M$ is divided in 8 equal intervals and estimates of $\beta_{E D P}$ are defined for the $3^{\text {rd }}$ through the $7^{\text {th }}$ intervals. These intervals contain a statistically significant sample size for estimating dispersions with the number of records ranging from a minimum of 21 to a maximum of 69. Other intervals contain a number of samples less than 20 , and by a convergence analysis has been observed that this number is not appropriate to have a confident estimate of the dispersion.

Fig. 8 and 9 show the dispersion for each interval of the $I M$ value for four demand parameters. They report the results for the structure dependent $I M s$ only. Fig. 8 (a) shows the 
results corresponding to the $1^{\text {st }}$ level interstory drift. In this case the use of $S_{a}\left(T_{1}\right), S_{d}\left(T_{1}\right)$ and $\mathrm{S}_{\mathrm{v}}\left(\mathrm{T}_{1}\right)$ lead to a higher variation of dispersion compared with $\mathrm{S}_{\mathrm{aCM}}\left(\mathrm{T}_{1}\right)$ and $\mathrm{S}_{\mathrm{aC}}\left(\mathrm{T}_{1}\right)$. This result can be attributed to the fact that for low values of the $I M$ the structural behavior is controlled by the elastic modal period, while, for events with higher intensity, the IMs that are able to account for the period elongation caused by post-elastic behavior are more efficient. $S_{\mathrm{di}}\left(T_{1}\right)$ presents an intermediate situation. For $S_{\mathrm{a}}\left(\mathrm{T}_{1}\right), \mathrm{S}_{\mathrm{d}}\left(\mathrm{T}_{1}\right), \mathrm{S}_{\mathrm{v}}\left(\mathrm{T}_{1}\right)$ and $\mathrm{S}_{\mathrm{di}}\left(\mathrm{T}_{1}\right)$ the maximum values of dispersion are respectively 4.59, 4.17, 4.54 and 3.31 times the minimum value. Differently, for $\mathrm{S}_{\mathrm{aC}}\left(\mathrm{T}_{1}\right)$ and $\mathrm{S}_{\mathrm{aCM}}\left(\mathrm{T}_{1}\right)$ the maximum values of dispersion are respectively 1.65 and 2.03 times the minimum value. Hence, with $\mathrm{S}_{\mathrm{aC}}\left(\mathrm{T}_{1}\right)$ and $\mathrm{S}_{\mathrm{aCM}}\left(\mathrm{T}_{1}\right)$ the homoscedasticity assumption is better satisfied. Moreover, it is possible to observe that in this case the dispersion increases with increasing seismic intensity. Fig. 8 (b) shows the variability of dispersion for the top story acceleration. It is observed that the homoscedasticity condition is better satisfied for this EDP. In this case, the ratio between the maximum and minimum dispersion values ranges from 1.15 to 1.48 . Fig. 9 shows the variability of dispersion for curvature and shear force for column C1-1. From Fig. 9 (a) it is possible to observe that the dispersion of the shear force is decreasing with the $I M$ value. This result is a consequence of the post-elastic behavior of the structural section that provides an upper limit on the shear demand, yielding a concentration of the demand values for larger IMs.
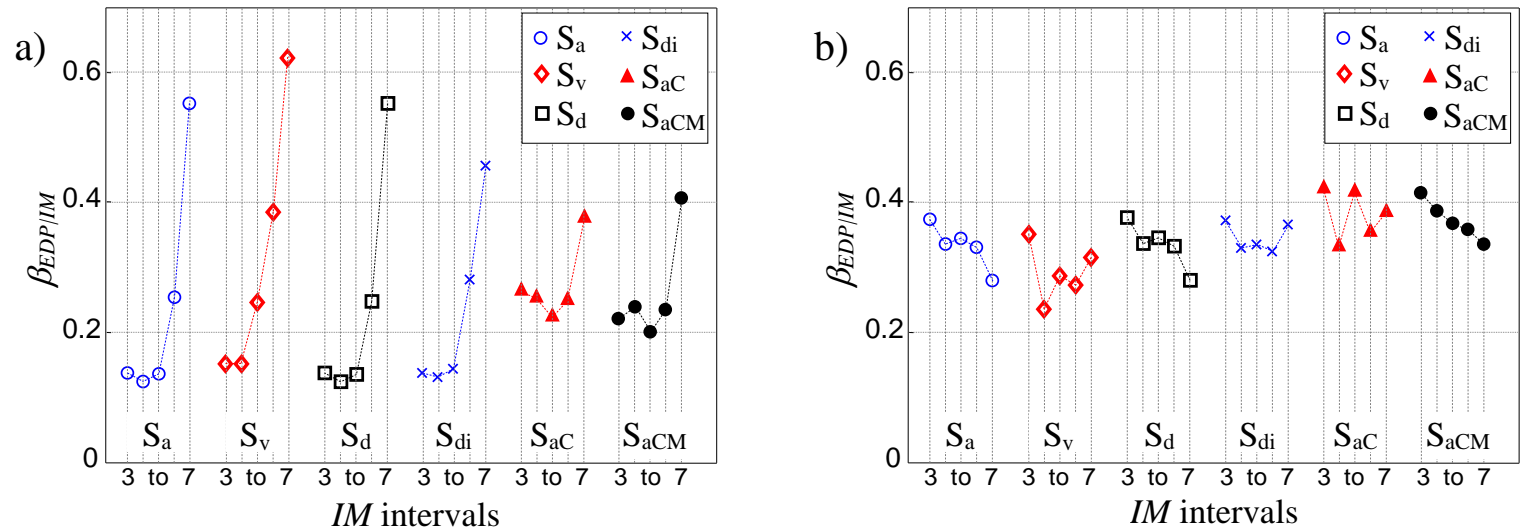

Fig. 8 Variation in dispersion of a) $1^{\text {st }}$ level interstory drift and b) Top story acceleration for the structure dependent IMS
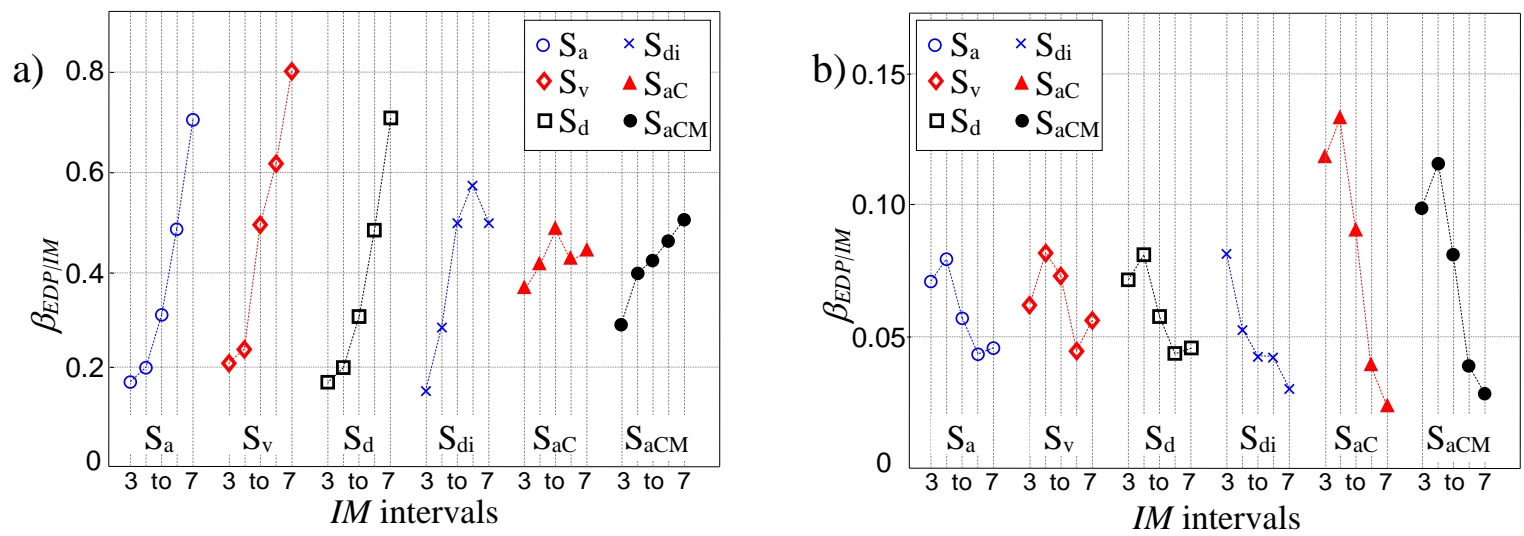

Fig. 9 Variation in dispersion of a) Curvature upper section of column C1-1 and b) Shear force of column C1-1 for the structure dependent IMs

Table 6 contains the variation ratio in dispersion $\beta_{E D P \max } / \beta_{E D P \min }$ across the range of 
ground motion intensity. Table 6 shows that overall, structure independent IMs conform better with the homoscedasticity assumption. The comparison of Tables 3 and 6 suggest that the homoscedasticity assumption is better satisfied while using IMs that are less efficient. This result is consequence of the fact that more efficient $I M S$ are also more sensitive to the variation of the structural properties of the system (i.e. when the structure undergoes nonlinear behavior and its effective natural period becomes significantly different from the elastic period). For intermediate and global deformational EDPs, the use of $\mathrm{S}_{\mathrm{ac}}\left(\mathrm{T}_{1}\right)$ and $\mathrm{S}_{\mathrm{aCM}}\left(\mathrm{T}_{1}\right)$ improves the homoscedasticity assumption of an approximately constant value of dispersion. This result is consistent with what has been already observed in past studies on global EDPs. However, the homoscedasticity assumption is never satisfied for local EDPs, regardless of $I M$ adopted. Thus, the use of heteroscedastic models is necessary when assessing the dispersion in probabilistic seismic demand modeling with these IMs. Aslani and Miranda (2005) provide some recommendations on the derivation of heteroscedastic models of the demand for global EDPs.

Table 6 Ratio $\beta_{E D P \max } / \beta_{E D P \text { min }}$ between maximum and minimum values of the dispersion (A value closer to 1.0 offers a proxy to indicate the validity of the homoscedasticity assumption)

\begin{tabular}{|c|c|c|c|c|c|c|c|c|c|c|c|c|}
\hline & & \multicolumn{6}{|c|}{ Structure dependent $I M s$} & \multicolumn{5}{|c|}{ Structure independent $I M s$} \\
\hline & n.comp. & $S_{a}$ & $S_{\mathrm{v}}$ & $S_{d}$ & $\mathrm{~S}_{\mathrm{di}}$ & $\mathrm{S}_{\mathrm{aC}}$ & $\mathrm{S}_{\mathrm{aCM}}$ & PGA & PGV & PGD & $\mathrm{S}_{\mathrm{a}-02 \mathrm{~s}}$ & $S_{\mathrm{a}-1 \mathrm{~s}}$ \\
\hline \multicolumn{13}{|c|}{ Local EDPS } \\
\hline$\varepsilon_{\mathrm{s}, \max }$ & 42 & 5.71 & 5.77 & 5.66 & 5.74 & 2.95 & 3.18 & 2.20 & 2.77 & 2.82 & 1.82 & 2.72 \\
\hline$\varepsilon_{c, \max }$ & 42 & 6.33 & 6.09 & 6.29 & 6.54 & 2.83 & 3.59 & 2.07 & 2.53 & 2.75 & 1.72 & 2.46 \\
\hline$\phi_{\max }$ & 42 & 4.20 & 4.52 & 4.19 & 4.20 & 4.66 & 4.16 & 2.65 & 3.64 & 3.01 & 2.61 & 4.30 \\
\hline$\sigma_{\mathrm{j}, \text { tens,max }}$ & 12 & 3.29 & 2.72 & 3.31 & 3.32 & 5.52 & 4.41 & 3.19 & 4.27 & 3.64 & 3.71 & 5.90 \\
\hline$\sigma_{\mathrm{j}, \mathrm{compr} \text { max }}$ & 12 & 3.19 & 2.94 & 3.21 & 3.03 & 5.93 & 4.31 & 3.17 & 4.78 & 4.10 & 3.77 & 6.42 \\
\hline $\mathrm{V}_{\max }$ & 21 & 4.41 & 6.24 & 4.38 & 5.54 & 4.41 & 4.25 & 2.42 & 3.72 & 3.51 & 2.05 & 2.78 \\
\hline $\mathrm{M}_{\max }$ & 42 & 4.09 & 3.85 & 4.09 & 4.04 & 4.78 & 4.31 & 3.14 & 3.37 & 3.21 & 2.77 & 4.91 \\
\hline \multicolumn{13}{|c|}{ Global and Intermediate $E D P S$} \\
\hline$\overline{V_{b, \max }}$ & 1 & 3.01 & 2.75 & 3.05 & 3.35 & 7.98 & 6.10 & 4.31 & 9.06 & 6.03 & 4.46 & 7.39 \\
\hline$\theta_{\mathrm{i}, \max }$ & 3 & 2.78 & 2.83 & 2.76 & 2.13 & 1.15 & 1.36 & 1.25 & 1.20 & 1.50 & 1.21 & 1.33 \\
\hline St.Vel & 3 & 1.40 & 1.32 & 1.40 & 1.38 & 1.52 & 1.70 & 1.32 & 1.13 & 1.13 & 1.39 & 1.74 \\
\hline St.Acc & 3 & 1.45 & 1.34 & 1.45 & 1.19 & 1.23 & 1.39 & 1.34 & 1.23 & 1.09 & 1.35 & 1.31 \\
\hline Average & 223 & 4.68 & 4.79 & 4.66 & 4.78 & 3.99 & 3.83 & 2.54 & 3.25 & 3.05 & 2.35 & 3.73 \\
\hline
\end{tabular}

5.2. Lognormal demand distribution assumption

The validity of the typical lognormal probability distribution assumption regarding the variation of the demand is investigated through a Kolmogorov-Smirnov goodness-of-fit test. This test is commonly used in order to evaluate if a sample set comes from a population with a specific distribution and it is based on the comparison between the empirical distribution function and the cumulative distribution function of the reference distribution at a particular confidence level. Further details can be found in common statistical analysis texts (e.g. Hines et al. 2003).

The hypothesis test with a confidence level of $85 \%$ is conducted for all of the considered $I M-E D P$ pairs for the intervals that contain a statistically significant number of samples. Fig. 10 shows the comparison between the numerical and theoretical cumulative distribution functions for the $4^{\text {th }}$ interval of the demand model (mean $I M$ value of $0.054 \mathrm{~g}$ ) for the $1^{\text {st }}$ 
interstory drift vs $S_{a}\left(T_{1}\right)$. The comparison is made by using the normal distribution in the logarithmic space. Table 7 shows the fraction of cases where the hypothesis tests is satisfied.

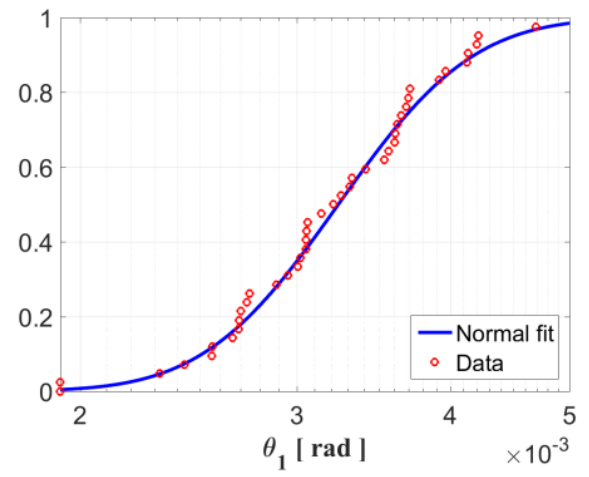

Fig. 10 Example test of lognormal distribution assumption. Comparison between the numerical and theoretical cumulative distribution functions of the demand for the $1^{\text {st }}$ interstory drift in the $4^{\text {th }}$ interval of the demand model. $\mathrm{S}_{\mathrm{a}}\left(\mathrm{T}_{1}\right)$ is the $I M$ employed in this example.

Table 7 Check of the demand lognormal distribution hypothesis: Fraction of components where it is satisfied (confidence level equal to $85 \%$ )

\begin{tabular}{|c|c|c|c|c|c|c|c|c|c|c|c|c|}
\hline & & \multicolumn{6}{|c|}{ Structure dependent $I M s$} & \multicolumn{5}{|c|}{ Structure independent $I M s$} \\
\hline & n.comp. & $\mathrm{S}_{\mathrm{a}}$ & $S_{v}$ & $S_{d}$ & $\mathrm{~S}_{\mathrm{di}}$ & $\mathrm{S}_{\mathrm{aC}}$ & $\mathrm{S}_{\mathrm{aCM}}$ & PGA & PGV & PGD & $\mathrm{S}_{\mathrm{a}-02 \mathrm{~s}}$ & $S_{\mathrm{a}-1 \mathrm{~s}}$ \\
\hline \multicolumn{13}{|c|}{ Local EDPs } \\
\hline$\varepsilon_{\mathrm{s}, \max }$ & 42 & 0.82 & 0.82 & 0.84 & 0.81 & 0.79 & 0.80 & 0.70 & 0.78 & 0.74 & 0.66 & 0.74 \\
\hline$\varepsilon_{\mathrm{c}, \max }$ & 42 & 0.82 & 0.85 & 0.84 & 0.84 & 0.82 & 0.81 & 0.71 & 0.77 & 0.77 & 0.66 & 0.75 \\
\hline$\phi_{\max }$ & 42 & 0.82 & 0.83 & 0.83 & 0.82 & 0.79 & 0.81 & 0.61 & 0.73 & 0.70 & 0.59 & 0.75 \\
\hline$\sigma_{\mathrm{j}, \text { tens,max }}$ & 12 & 0.84 & 0.84 & 0.83 & 0.81 & 0.76 & 0.83 & 0.62 & 0.70 & 0.65 & 0.61 & 0.81 \\
\hline$\sigma_{\mathrm{j}, \mathrm{compr}, \max }$ & 12 & 0.78 & 0.80 & 0.82 & 0.78 & 0.72 & 0.82 & 0.55 & 0.65 & 0.62 & 0.55 & 0.75 \\
\hline $\mathrm{V}_{\max }$ & 21 & 0.80 & 0.77 & 0.83 & 0.73 & 0.80 & 0.68 & 0.85 & 0.83 & 0.80 & 0.80 & 0.82 \\
\hline $\mathbf{M}_{\max }$ & 42 & 0.78 & 0.80 & 0.79 & 0.78 & 0.75 & 0.80 & 0.61 & 0.70 & 0.67 & 0.62 & 0.76 \\
\hline \multicolumn{13}{|c|}{ Global and Intermediate $E D P s$} \\
\hline $\mathrm{V}_{\mathrm{b}, \max }$ & 1 & 0.80 & 0.80 & 0.80 & 0.80 & 0.80 & 1.00 & 0.60 & 0.60 & 0.60 & 0.60 & 0.80 \\
\hline$\theta_{\mathrm{i}, \max }$ & 3 & 0.93 & 0.93 & 0.93 & 1.00 & 0.87 & 0.93 & 0.93 & 0.87 & 0.93 & 0.87 & 0.93 \\
\hline St.Vel & 3 & 1.00 & 1.00 & 1.00 & 1.00 & 0.73 & 0.93 & 0.87 & 0.87 & 0.80 & 0.80 & 1.00 \\
\hline St.Acc & 3 & 0.93 & 0.93 & 0.93 & 0.93 & 0.93 & 1.00 & 0.87 & 0.93 & 0.93 & 0.93 & 1.00 \\
\hline Average & 223 & 0.82 & 0.82 & 0.83 & 0.81 & 0.79 & 0.80 & 0.68 & 0.75 & 0.72 & 0.65 & 0.77 \\
\hline
\end{tabular}

The structure dependent $I M s$ tend to produce demand variations that conform to the traditionally assumed lognormal distribution. Among all, the fraction of components where the hypothesis test is satisfied for structure dependent $I M s$ is higher than that of structure independent $I M s$. In addition to the $I M$ considered, the validity of the assumed distribution also depends upon the EDP of interest. Although exceptions exist, the variation in global and intermediate responses tends more often to follow a lognormal distribution than in local level parameters. However, the combination of a local level parameter with a structure dependent $I M$ conforms reasonably well to the traditional assumption of a lognormal distribution at the $85 \%$ confidence level.

\section{Conclusions}

This paper investigates the effectiveness of probabilistic seismic demand models in the 
description of local EDP responses for the assessment of low-ductility RC frames. Several $E D P s$ have been considered in order to monitor the most relevant failure modes, and demand models of structural components are developed for these EDPs, providing insight into the appropriate form of regression model. Hypothesis tests on the typical lognormal distribution of demand and variation of the demand uncertainty with the $I M$ are performed. Additionally, several $I M s$ are analyzed and compared to identify which is the most appropriate to be used for each local EDP on the basis of IM properties such as: practicality, efficiency, sufficiency and hazard computability. A typical gravity load designed low-ductility RC frame is chosen as case study and validation of the finite element model is performed using published experimental data. Among the traditional and scalar IMs relatively easy to use, $11 \mathrm{IMs}$ are considered in this study. Moreover, 11 EDPs indicative of damage potential to RC buildings are considered among local, intermediate and global response quantities. To construct the demand models for all IM-EDP pairs and structural components, non-linear dynamic analyses are conducted on the validated model by using a set of 240 ground motions.

The study confirms that linear regression models (in the log-log space) provide a good fit of the demand for conventionally used global EDPs and for intermediate EDPs. Differently, for local EDPs, such as curvature, bending moments, shear force, joint stresses, or material strains, bilinear regression models are required. Deformation-based EDPs (i.e. $\phi_{\max }, \varepsilon_{\mathrm{s}, \max }$, $\left.\varepsilon_{\mathrm{c}, \max }\right)$ are characterized by a higher slope of the second segment of the bilinear regression and by a dispersion that increases with the $I M$ value. With force-based EDPs (i.e. $\mathrm{M}_{\max }, \mathrm{V}_{\max }$, $\left.\sigma_{\mathrm{j}, \text { tens,max }}, \sigma_{\mathrm{j}, \text { comp,max }}\right)$, there is the opposite situation. These results are regularly observed regardless of the considered $I M$. Consistent with global and intermediate EDPs, assessment of the demand dispersions indicates that structure dependent $I M s$ are more efficient for all considered EDPs relative to the structure independent $I M s$, with approximately 50\%-75\% lower dispersion $\left(\beta_{E D P}\right)$. Among the structure independent $I M s, \mathrm{PGV}$ and $\mathrm{S}_{\mathrm{a}-1 \mathrm{~s}}$ are the most efficient while $\mathrm{S}_{\mathrm{a}-02 \mathrm{~s}}$ and PGA produce the largest values of dispersion. Among the structure dependent $I M s, \mathrm{~S}_{\mathrm{a}}\left(\mathrm{T}_{1}\right), \mathrm{S}_{\mathrm{d}}\left(\mathrm{T}_{1}\right)$ and $\mathrm{S}_{\mathrm{di}}\left(\mathrm{T}_{1}\right)$ have the lowest $\beta_{E D P}$, while $\mathrm{S}_{\mathrm{v}}\left(\mathrm{T}_{1}\right), \mathrm{S}_{\mathrm{aCM}}\left(\mathrm{T}_{1}\right)$ and $\mathrm{S}_{\mathrm{aC}}\left(\mathrm{T}_{1}\right)$ are all moderately efficient. Overall, it is possible to observe that force-based EDPs are characterized by a lower dispersion. The sufficiency test of each $I M$ with respect to magnitude and source to site distance indicates that among all considered IM-EDP pairs, PGA and $S_{a-02 s}$ are insufficient with respect to magnitude, while PGD, is found to be insufficient with respect to distance for most of the EDPs. PGV best satisfies the sufficiency hypothesis with respect to both distance and magnitude, while all other $I M s$ were found to be equally sufficient.

The homoscedasticity assumption is evaluated for all of the demand models showing that for local EDPs this condition is not satisfied, regardless of IM. Thus, the variability of the dispersion should be taken into account when defining fragility curves of the RC building components. While structure independent IMs show improved conformance in terms of homoscedasticity for global and intermediate EDPs, this outcome is an artifact of the poor efficiency and overall high dispersion in the models, which is not ideal.

Kolmogorov-Smirnov goodness-of-fit tests are conducted to investigate the validity of the commonly used assumption of the lognormal probability distribution of the demand, revealing the superiority of the structure dependent $I M S$ to satisfy this assumption. The variation in global and intermediate responses tends more often to follow a lognormal distribution than in local level parameters; however, the combination of a local parameter with a structure dependent $I M$ conforms reasonably well to the traditional assumption of 
lognormal distribution of the demand.

The $I M$ properties do not show dependence upon the $E D P$ of interest and similar results can be observed looking at each EDP independently. Overall, $\mathrm{S}_{\mathrm{di}}\left(\mathrm{T}_{1}\right), \mathrm{S}_{\mathrm{d}}\left(\mathrm{T}_{1}\right)$ and $\mathrm{S}_{\mathrm{a}}\left(\mathrm{T}_{1}\right)$ are found to best satisfy all the requirements. This finding is consistent with other studies performed considering global EDPs only. However, it is important to consider also that while for $S_{d}\left(T_{1}\right)$ and $S_{a}\left(T_{1}\right)$ hazard curves are available, attenuation relationships for $S_{d i}\left(T_{1}\right)$ are usually not available and hence, the use of this $I M$ may be limited due to problems in the hazard definition. Regardless of the $I M$ adopted, the use of bilinear regression models and heteroscedastic models of the demand is suggested for such local EDPs in order to reduce uncertainties and to improve the predictive capabilities of the demand model and confidence in the risk assessment.

The present paper provides insights for the application of a probabilistic componentsbased approach, which provides a more comprehensive understanding of the structural behavior important for seismic risk assessment, seismic retrofit prioritization and life cycle cost assessment. In particular, results from the study can influence the definition of probabilistic seismic demand models able to describe local failure mechanisms and the choice of adequate IMs. The findings support the derivation of local fragility curves of damage to structural components or elements for probabilistic assessment of low-ductility RC frames. However, further investigation is needed for the definition of the models to account for the variation of the dispersion and the system logic for the definition of the system fragility, depending on the prospective (e.g. downtime, economic losses) and/or consequence modeling which is strongly linked to the structural behavior at component level. Finally, the results of this study are derived from extensive analysis (e.g. evaluation of 121 IM-EDP pairs) using a case study structure with validated numerical model. Exploration of alternative systems is warranted before generalizing these results. This paper, however, suggests a systematic approach for such an extended analysis.

\section{Appendix}

\section{Case Study: Description and validation of the numerical model}

The selected case study is a three-story gravity load designed RC moment resisting frame and it was largely experimentally tested by Bracci et al. (1992a,b) and Aycardi et al. (1992). Earthquake loads are neglected and no lateral load is considered for the design. Fig. 2 contains the general layout of the structure. Columns have a $300 \times 300 \mathrm{~mm}^{2}$ square section while beams are $230 \times 460 \mathrm{~mm}^{2}$ at each floor. The provision of ACI 318-89 code, Grade 40 steel $\left(f_{y}=276 \mathrm{MPa}\right)$ and concrete with compression resistance $f_{c}=24 \mathrm{MPa}$, were employed in the design.

A two dimensional model of the structure is developed by using OpenSees (McKenna et al. 2006) and employs 'Beam with Hinges' elements (Scott and Fenves 2006) to model the non-linear behavior of beams and columns. The beams are modeled by using a T-section where the effective width of the slab is assumed to be four times the beam width based on the ACI 318. In the plastic hinge zone, the behavior of concrete and steel reinforcement is described respectively by the Concrete 02 and the Hysteretic material model. The plastic hinge length for both beams and columns is evaluated based on Panagiotakos and Fardis (2001). The elastic part of each element is modeled with an effective flexural stiffness, evaluated through moment-curvature analysis, for the axial force level induced by the dead loads. The effective flexural stiffness is evaluated by the ratio of the moment and the 
curvature corresponding to the yielding of the first rebar of the section. Beam-column joints are modeled as rigid, while the rigid-floor diaphragm is modeled by assigning a high value to the axial stiffness of the beams. Masses are concentrated at the beam-column connections. The modal period of the full scale model is equal to $1.323 \mathrm{sec}$.

The developed finite element model is validated by comparing the numerical with the available experimental results at the global as well as local level. Aycardi et al. (1992) report the results concerning four 1:3 scale column specimens. Fig. 11 shows the comparisons between the experimental and the simulated results concerning one column specimen. Fig. 11 (a) contains the comparison of the lateral load-drift behavior while Fig. 11 (b) shows the comparison of the external work limited to the 6 displacement cycles with drift amplitude from $2 \%$ up to $4 \%$. The simulated test results show a satisfactory agreement with the experimental results.
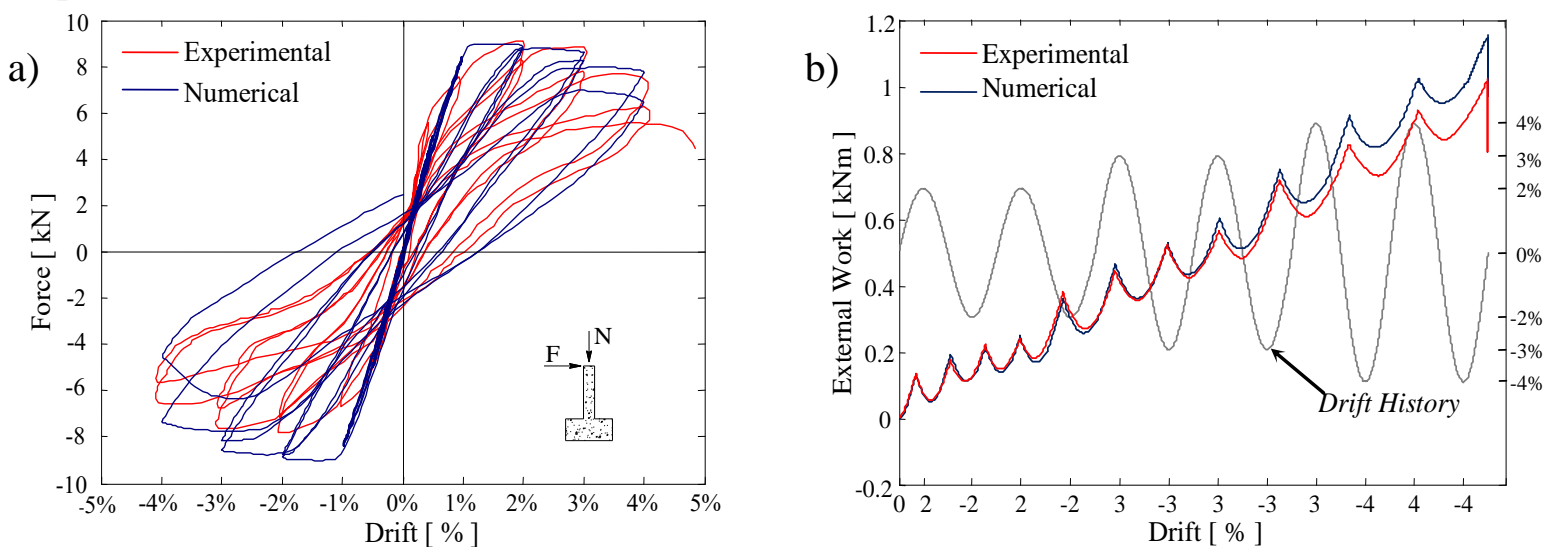

Fig. 11 Experimental and numerical comparison for Column specimen 1, a) Lateral Load-Drift Behavior, b) External work

Bracci et al. (1992a,b) report the results of the experimental tests carried on the 1:3 scale frame. The first three natural periods measured in the experimental test results $(0.538,0.177$ and $0.119 \mathrm{sec}$ ) are in close agreement with the periods provided by the 1:3 scale numerical model with uncracked gross stiffness properties $(0.561,0.180$, and $0.110 \mathrm{sec}$ ). Shaking table tests were also performed by applying the Kern County 1952, Taft Lincoln School Station, N021E component record scaled for different levels of the seismic intensity (PGA equal to $0.05 \mathrm{~g}, 0.20 \mathrm{~g}$ and $0.30 \mathrm{~g}$ ). Fig. 12 shows the comparison between the $1^{\text {st }}, 2^{\text {nd }}$ and $3^{\text {rd }}$ story displacements of the 1:3 scale experimental and numerical model with the three ground motion intensities. Due to space constrains the comparison is shown only for the first 10 seconds.

Damping sources other than the hysteretic dissipation of energy are modeled through the Rayleigh damping matrix. Mass and stiffness related coefficients are calibrated such that the values of the damping factor of $3 \%$ are obtained for the first two vibration modes. The agreement between the numerical and experimental response history is quite satisfactory for values of the PGA equal to $0.05 \mathrm{~g}$ and $0.20 \mathrm{~g}$, while for PGA equal to $0.30 \mathrm{~g}$ the agreement is not as good. However, it should be stressed that only the peak values of the response are of interest for the development of fragility curves and that the simulated peak values are very close to the experimental peak values for all the seismic intensity levels considered. Additional information regarding the modeling and the validation are reported in Freddi et al. (2013). 

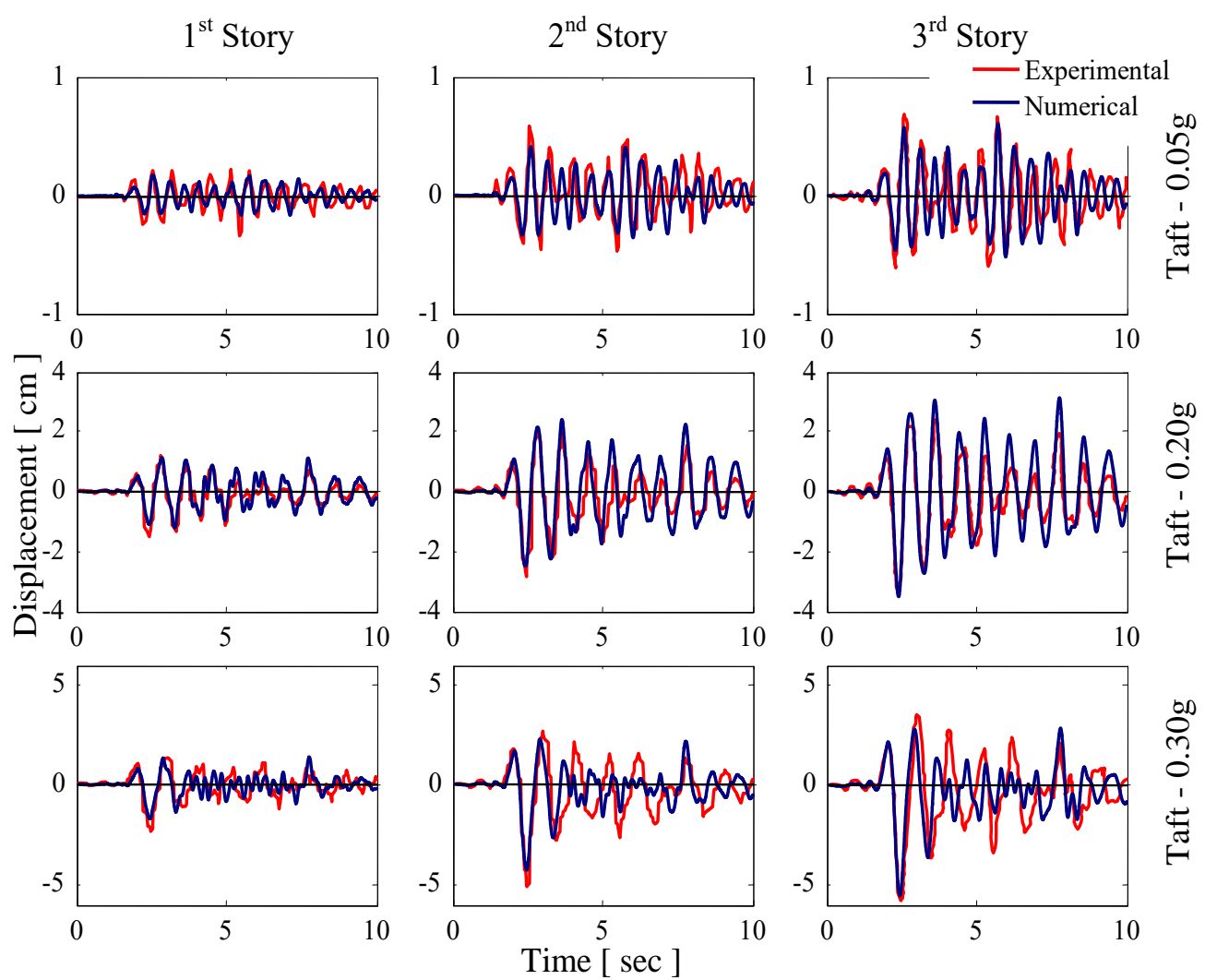

Fig. 12 Comparison of dynamic analysis for model validation. Numerical and Experimental Story displacement history subjected to the Taft record with PGA equal to $0.05 \mathrm{~g}, 0.20 \mathrm{~g}$ and $0.30 \mathrm{~g}$

\section{Acknowledgements}

This material is based in part upon work supported by the National Science Foundation under grant number CMMI-1041607. Any opinions, findings, and conclusions or recommendations expressed in this material are those of the authors and do not necessarily reflect the views of the National Science Foundation.

\section{References}

ACI 318 (2002) Building Code Requirements for Structural Concrete and Commentary. American Concrete Institute

Alavi B, Krawinkler H (2004) Behavior of moment-resisting frame structures subjected to near-fault ground motions. Earthq Eng Struct Dyn 33(6):687-706

Aslani H, Miranda E (2005) Probability-based seismic response analysis. Eng Struct 27:1151-1163

ATC 58 (2004) Project Task Report, Phase 2, Task 2.2, Engineering Demand Parameters for Structural Framing System. Applied Technology Council

Aycardi LE, Mander JB, Reinhorn AM (1992) Seismic Resistance of Reinforced Concrete Frame Structures Designed Only for Gravity Loads - Part II: Experimental Performance of Subassemblages. Report NCEER-92-0028, Buffalo, New York

Bai JW, Gardoni P, Hueste MBD (2011) Story-specific demand models and seismic fragility estimates for multi-story buildings. Struct Saf 33:96-107 
Baker JW, Cornell CA (2005) A vector-valued ground motion intensity measure consisting of spectral acceleration and epsilon. Earthq Eng Struct Dyn 34:1193-1217

Baker JW, Jayaram N, Shahi S (2011) New Ground Motion Selection Procedures and Selected Motions for the PEER Transportation Research Program. PEER Technical Report 2011/03, Berkeley, CA

Bracci JM, Reinhorn AM, Mander JB (1992a) Seismic Resistance of Reinforced Concrete Frames Structures Designed only for Gravity Loads - Part I: Design and Properties of a 1/3 Scale Model Structure. Report NCEER-92-0027, Buffalo, New York

Bracci JM, Reinhorn AM, Mander JB (1992b) Seismic Resistance of Reinforced Concrete Frame Structures Designed Only for Gravity Loads - Part III: Exp Performance and Analytical Study of a Model. Report NCEER-92-0029, Buffalo, New York

Celik OC, Ellingwood BR (2010) Seismic fragilities for non-ductile reinforced concrete frames - Role of aleatoric and epistemic uncertainties. Struct Saf 32(1):1-12

Conte JP, Pandit H, Stewart JP, Wallace JW (2003) Ground motion intensity measures for performance-based earthquake engineering. In: ICASP 9, San Francisco, CA

Cordova PP, Deierlein GG, Mehanny SSF, Cornell CA (2000) Development of a twoparameter seismic intensity measure and probabilistic assessment procedure. In: $2^{\text {nd }}$ USJapan workshop on performance-based earthquake engineering for reinforced concrete building structures, Sapporo, Hokkaido, Japan

Cornell CA, Krawinkler H (2000) Progress and challenges in seismic performance assessment. PEER Center News 3(2), Spring 2000

Cornell CA, Jalayer F, Hamburger RO, Foutch DA (2002) Probabilistic Basis for 2000 SAC Federal Emergency Management Agency Steel Moment Frame Guidelines. J Struct Eng 128(4): 526-533

EC8 (2005) Eurocode 8: Design of structures for earthquake resistance - Part 1: general rules, seismic actions and rules for buildings.

Elwood KJ, Moehle JP (2005) Drift Capacity of Reinforced Concrete Columns with Light Transverse Reinforcement. Earthq Spectra 21:71-89

FEMA (2000) Prestandard and Commentary for the Seismic Rehabilitation of Buildings, FEMA 356. Federal Emergency Management Agency, Washington DC

FEMA. (2012) Seismic performance assessment of buildings, FEMA P-58-1. Applied Technology Council for the Federal Emergency Management Agency, Washington, DC

Freddi F, Tubaldi E, Ragni L, Dall'Asta A (2013) Probabilistic performance assessment of low-ductility reinforced concrete frame retrofitted with dissipative braces. Earthq Eng Struct Dyn 42:993-1011

Ghosh J, Padgett JE (2011) Probabilistic seismic loss assessment of aging bridges using a component-level cost estimation approach. Earthq Eng Struct Dyn 40(15):1743-1761

Giovenale P, Cornell CA, Esteva L (2004) Comparing the adequacy of alternative ground motion intensity measures for the estimation of structural responses. Earthq Eng Struct Dyn 33:951-79

HAZUS (2009) Earthquake model. HAZUS-MH 2.0: Technical Manual. Federal Emergency Management Agency, Washington DC

Hines WW, Montgomery DC, Goldsman DM, Borror CM (2003) Probability and Statistic in Engineering. Wiley, New York

Hueste MBD, Bai JW (2007) Seismic retrofit of a reinforced concrete flat-slab structure: Part II - Seismic fragility analysis. Eng Struct 29(6):1178-1188 
Jalayer F (2003) Direct Probabilistic Seismic Anaysis: Implementing Non-linear Dynamic Assessments. Ph.D. dissertation, Dept. of Civil and Environmental Engineering, Stanford Univ., Stanford, CA.

Kappos AJ, Chryssanthopoulos MK, Dymiotis C (1999) Uncertainty analysis of strength and ductility of confined reinforced concrete members. Engineering Structures, 21: 195-208

Katsanos EI, Sextos AG, Manolis GD (2010) Selection of earthquake ground motion records: A state-of-the-art review from a structural engineering prospective. Soil Dyn Earthq Eng 30:157-169

Kazantzi AK, Vamvatsikos D (2015) Intensity measure selection for vulnerability studies of building classes. Earthq Eng Struct Dyn 44(15): 2677-2694.

Fajfar P, Dolšek M (2012) A practice-oriented estimation of the failure probability of building structures. Earthq Eng Struct Dyn 41(3):531-547

Liel AB, Deierlein GG (2012) Using Collapse Risk Assessments to Inform Seismic Safety Policy for Older Concrete Buildings. Earthq Spectra 28(4): 1495-1521

Lin L, Naumoski N, Saatcioglu M, Foo S (2011) Improved intensity measures for probabilistic seismic demand analysis. Part 1: Development of improved intensity measures, Can J Civ Eng 38:79-88

Luco N, Bazzurro P (2007) Does amplitude scaling of ground motion records results in biased nonlinear structural drift responses? Earthq Eng Struct Dyn 36(13):1813-1835

Luco N, Cornell CA (2007) Structure-specific scalar intensity measures for near-source and ordinary earthquake ground motions. Earthq Spectra 23:357-392

Mackie K, Stojadinovic B (2003) Seismic Demands for Performance-Based Design of Bridges. PEER Report No. 2003/13, Berkeley, CA

McKenna F, Fenves GL, Scott MH (2006) OpenSees: Open system for earthquake engineering simulation. PEER Center, Berkeley, CA

Medina RA, Krawinkler H (2003) Seismic demand for nondeteriorating frame structures and their dependence on ground motions. Blume Report No. 144, Stanford, CA

Moehle J, Deierlein GG (2004) A Framework methodology for performance-based earthquake engineering. In: $13^{\text {th }}$ WCEE, Vancouver, Canada

NIST (2010) Applicability of Nonlinear Multiple-Degree-of-Freedom Modeling for Design. Report No. NIST GCR 10-917-9, prepared for the US National Institute of Standards and Technology by the NEHRP Consultants Joint Venture, Gaithersburg, MD

Padgett JE, Nielson BG, DesRoches R (2008) Selection of optimal intensity measures in probabilistic seismic demand models of highway bridge portfolios. Earthq Eng Struct Dyn 37:711-725

Panagiotakos TB, Fardis MN (2001) Deformations of reinforced concrete members at yielding and ultimate. ACI Struct J 98:135-148

Ramamoorthy SK, Gardoni P, Bracci JM (2006) Probabilistic demand models and fragility curves for reinforced concrete frames. J Struct Eng 132(10):1563-72

Scott MH, Fenves GL (2006) Plastic hinge integration methods for force-based beam-column elements. J Struct Eng 132:244-252

Tothong P, Luco N (2007) Probabilistic seismic demand analysis using advanced ground motion intensity measures. Earthq Eng Struct Dyn 36:1837-1860

Tubaldi E, Barbato M, Dall'Asta (2012) Influence of model parameter uncertainty on seismic transverse response and vulnerability of steel-concrete composite bridge with dual load path. J Struct Eng 138(3): 363-374 
Tubaldi E, Freddi F, Barbato M (2016) Probabilistic seismic demand model for pounding risk assessment. Earthq Eng Struct Dyn (DOI: 10.1002/eqe.2725)

Vamvatsikos D, Cornell CA (2002) Incremental dynamic analysis. Earthq Eng Struct Dyn 31(3): 491-514 